\title{
Review Article \\ Clinical Pharmacology of Midazolam in Neonates and Children: Effect of Disease-A Review
}

\author{
Gian Maria Pacifici \\ Section of Pharmacology, Department of Translational Research and New Technologies in Medicine and Surgery, \\ Medical School, University of Pisa, 56126 Pisa, Italy \\ Correspondence should be addressed to Gian Maria Pacifici; pacifici@biomed.unipi.it
}

Received 9 November 2013; Accepted 26 December 2013; Published 18 February 2014

Academic Editor: Steven M. Donn

Copyright (C) 2014 Gian Maria Pacifici. This is an open access article distributed under the Creative Commons Attribution License, which permits unrestricted use, distribution, and reproduction in any medium, provided the original work is properly cited.

\begin{abstract}
Midazolam is a benzodiazepine with rapid onset of action and short duration of effect. In healthy neonates the half-life $\left(t_{1 / 2}\right)$ and the clearance $(\mathrm{Cl})$ are 3.3-fold longer and 3.7-fold smaller, respectively, than in adults. The volume of distribution $(\mathrm{Vd})$ is $1.1 \mathrm{~L} / \mathrm{kg}$ both in neonates and adults. Midazolam is hydroxylated by CYP3A4 and CYP3A5; the activities of these enzymes surge in the liver in the first weeks of life and thus the metabolic rate of midazolam is lower in neonates than in adults. Midazolam acts as a sedative, as an antiepileptic, for those infants who are refractory to standard antiepileptic therapy, and as an anaesthetic. Information of midazolam as an anaesthetic in infants are very little. Midazolam is usually administered intravenously; when minimal sedation is required, intranasal administration of midazolam is employed. Disease affects the pharmacokinetics of midazolam in neonates; multiple organ failure reduces the $\mathrm{Cl}$ of midazolam and mechanical ventilation prolongs the $t_{1 / 2}$ of this drug. ECMO therapy increases $t_{1 / 2}, \mathrm{Cl}$, and $\mathrm{Vd}$ of midazolam several times. The adverse effects of midazolam in neonates are scarce: pain, tenderness, and thrombophlebitis may occur. Respiratory depression and hypotension appear in a limited percentage of infants following intravenous infusion of midazolam. In conclusion, midazolam is a safe and effective drug which is employed as a sedative, as antiepileptic agent, for infants who are refractory to standard antiepileptic therapy, and as an anaesthetic.
\end{abstract}

\section{Introduction}

Midazolam is a short-acting benzodiazepine with rapid onset of action. It has anxiolytic, muscle relaxant, and anticonvulsant activity, now most widely used to generate anterograde amnesia and to stop prolonged seizures in children [1]. Midazolam is one of the most widely used sedatives in the "neonatal intensive care unit" [2]. The sedative and anticonvulsant properties of midazolam are related to GABA accumulation and occupation of benzodiazepine receptors [3]. Antianxiety properties are related to increasing the glycine inhibitory neurotransmitter [3].

Midazolam exerts most of its effects by interacting with inhibitory neurotransmitter receptors directly activated by GABA. $\mathrm{GABA}_{\mathrm{A}}$ receptors are responsible for most inhibitory neurotransmission in the central nervous system. Benzodiazepines act at $\mathrm{GABA}_{\mathrm{A}}$ receptors by binding directly to a specific site that is distinct from that of GABA binding [4]. Midazolam, which was approved for clinical use in 1976, acts as a sedative-hypnotic, is used in the treatment of refractory seizures, and induces anaesthesia [3].

In adults, the half-life $\left(t_{1 / 2}\right)$ of midazolam is 1.9 hours, which is 22 -fold shorter than that of diazepam [5]. Bioavailability of midazolam is about $50 \%$ when absorbed directly through either oral or nasal mucosa [6]. Midazolam is mainly eliminated by hydroxylation to form 1-hydroxymidazolam by CYP3A4 and CYP3A5 enzymes. 1-Hydroxymidazolam has sedative effect [4]. Finally, this metabolite is glucuronidated before excretion into urine [7]. Hepatic CYP3A4 activity appears in the liver during the first weeks of life $[8,9]$; it is thus lower in neonate than adult liver, resulting in reduced midazolam clearance $(\mathrm{Cl})$ in neonates $[6,10]$. CYP3A5 expression has been detected in only $10 \%$ to $30 \%$ of neonate liver samples tested [11]. Elimination $t_{1 / 2}$ of midazolam is shorter in neonates; it is about from 4 to 6 hours. It is quite variable and may be up to 22 hours in premature infants [3]. CYP3A4 and CYP3A5 activities reach adult levels between 3 and 12 months of postnatal age [9]. Midazolam is highly 
bound to plasma protein; in adults, the bound percentage is 98 [5].

The literature on the effects and fate of midazolam in neonates is scarce. Most of the published information deals with the sedative effect, with the treatment of refractory seizures to standard therapies, with the metabolism, with the pharmacokinetics, and with the adverse effects of midazolam. The information on the use of midazolam as an anesthetic agent in newborn infants is lacking. Mellon et al. [12] reviewed the anaesthetic agents in newborn animals. Information on the anaesthetic activity of midazolam has been reported in Sprague-Dawley rats [13] and in mice C57BL6 [14]; both animals were 7 days old. No data on the anaesthesia by midazolam in infants are available.

Infants may experience moderate to severe pain in the "neonatal intensive care unit" and the use of a sedative to make their life comfortable when undergoing painful procedures is useful [15]. Midazolam was found to be more effective than placebo as a sedative in neonates [16] and its concentrations ranging from 100 to $400 \mathrm{ng} / \mathrm{mL}$ are sufficient for sedation [17]. Jacqz-Aigrain et al. [16], Anand et al. [18], and Arya and Ramji [19] used midazolam for sedation of neonates undergoing mechanical ventilation and midazolam has resulted to be a safe and effective sedation.

Benzodiazepines provide effective control of patient agitation and these drugs are useful to comfort neonates during stressing procedures. Midazolam represents a convenient choice among the sedatives because of its fast onset of action and rapid termination of effect and is thus frequently used in the "neonatal intensive care units."

Up to now, little has been done to make comfortable the life of neonates who undergo stress and pain. Lowrie et al. [20] created a "pediatric sedation unit" to uniform and monitor the therapy for sedation and/or analgesia for children undergoing invasive and noninvasive procedures. Infants admitted to the "pediatric sedation unit" were assessed medically for risk factors during sedation. Many of the pediatric patients admitted to this unit were neonates. Pharmacological treatment helps neonates to tolerate pain procedures or diagnostic studies requiring prolonged periods of immobility. The majority of children needing sedation received midazolam or propofol [20].

$\mathrm{Ng}$ et al. [21] reviewed the literature on the intravenous midazolam infusion for sedation of infants in the "neonatal intensive care unit." Three trials were included in the study and using different sedation scales each study showed a higher sedation level in the midazolam group compared to the placebo. However, $\mathrm{Ng}$ et al. [21] conclude that there are insufficient data to promote the use of intravenous midazolam infusion as a sedative for neonates undergoing intensive care [22].

Sedation may be performed with opioids (fentanyl, morphine, and diamorphine) or with the sedative-hypnotic midazolam in ventilated neonates. Endotracheal intubation and mechanical ventilation are major components of routine intensive care for very low birthweight newborn infants and sick fullterm newborn infants [22]. Sedation is widely used in neonates, although there is limited clinical evidence for the efficacy and safety of the drugs used or the methods of administering them [22].

A useful action of midazolam is the management of neonatal seizures refractory to conventional treatments. $\mathrm{Hu}$ et al. [23] reported that a continuous intravenous infusion of midazolam, ranging from 1 to $15 \mu \mathrm{g} / \mathrm{kg}$ per min, with an average of $4 \mu \mathrm{g} / \mathrm{kg}$ per min, terminated the seizures in 32 infants whose seizures could not be controlled by diazepam, phenytoin, or phenobarbital. Castro Conte et al. [24] found that midazolam $(0.15 \mathrm{mg} / \mathrm{kg}$ intravenous bolus, followed by a continuous infusion of $1 \mu \mathrm{g} / \mathrm{kg}$ per min, increasing by 0.5 to $1 \mu \mathrm{g} / \mathrm{kg}$ every $2 \mathrm{~min}$, until a maximum of $18 \mu \mathrm{g} / \mathrm{kg}$ per min) controlled the seizures in 13 neonates refractory to the treatment with phenobarbital and phenytoin.

Troponin $\mathrm{T}$ is a prognostic indicator of postoperative recovery. Midazolam, propofol, or sevoflurane had similar efficacy in the production of troponin $\mathrm{T}$ in infants who underwent cardiac surgery [25].

The information on the effects of midazolam and on the fate of this drug in neonates has been published in different journals during the last thirty years and it is scattered. The aims of this article are (1) to gather together and (2) to review the published data on (a) the metabolism and (b) the pharmacokinetics of midazolam in neonates, (c) the therapeutic effects, and finally (d) the adverse effects of midazolam in neonates. The main objective of this work is (e) to provide neonatologists with a tool that embraces all aspects of the clinical pharmacology of midazolam in neonates. Little is known about the effects and the fate of the drugs administered to neonates. This review was written to help the neonatologists, hoping that they will find some useful information and thus some advantages for their work, from reading the present paper.

\section{Bibliographic Search}

The bibliographic search was performed electronically using PubMed and EMBASE databases as search engines; September 2013 was the cutoff point. The following key words: "midazolam neonate," "midazolam mechanism of action," "midazolam therapy neonate," "midazolam pharmacokinetics neonate," "midazolam metabolism neonate," "CYP3A4 midazolam neonate," "CYP3A5 midazolam neonate," "oral administration midazolam neonate," "intranasal administration of midazolam neonates," "midazolam seizures," "midazolam anaesthesia neonate," and "midazolam adverse effects neonate," were used. The bibliography of each article was read carefully, and the selected articles were examined. In addition, the books NEOFAX: a Manual Used in the Neonatal Care, by Young and Mangum [3], and the Neonatal Formulary [1] were consulted. The findings of the bibliographic search gave rise to 101 original articles, 13 review articles, and 6 book chapters. The publication years of this matter ranged from 1979 to 2013.

\section{Results}

3.1. Doses of Midazolam in Neonates. For sedation, Young and Neofax [3] suggest giving intravenously a 50 to $150 \mu \mathrm{g} / \mathrm{kg}$ 
of midazolam over at least $5 \mathrm{~min}$. Midazolam may also be administered intramuscularly. Repeat as required, usually Q2 to 4 hours. Dosage requirements are decreased by concurrent use of narcotics. For continuous intravenous infusion, give a 10 to $60 \mu \mathrm{g} / \mathrm{kg}$ midazolam per hour. Dosage of this drug may need to be increased after several days of therapy because of development of tolerance and/or increase of $\mathrm{Cl}$. For Intranasal administration, give a 200 to $300 \mu \mathrm{g} / \mathrm{kg}$ midazolam per dose using $5 \mathrm{mg} / \mathrm{mL}$ injectable form. For sublingual administration, give a $0.2 \mathrm{mg} / \mathrm{kg}$ per dose of midazolam using $5 \mathrm{mg} / \mathrm{mL}$ injectable form mixed with small amounts of flavoured syrup. For Oral administration, give $250 \mu \mathrm{g}$ per dose. For Anticonvulsant therapy; give intravenously a loading dose of $150 \mu \mathrm{g} / \mathrm{kg}$ over at least $5 \mathrm{~min}$ followed by a maintenance infusion dose of 60 to $400 \mu \mathrm{g} / \mathrm{kg}$ per hour (1 to $7 \mu \mathrm{g} / \mathrm{kg}$ per $\min )$.

3.2. Metabolism of Midazolam in Neonates. Development has a profound effect on the expression of phase I enzymes such as the cytochromes P450 (CYPs). Distinct patterns of isoform specific development CYP expression have been observed postnatally. Although the CYP content in the fetal liver equals about 30 to $60 \%$ of adult values [35], isoforms have a specific ontogeny and preclude the generalisation of a simple single developmental pattern for overall CYP activities, necessitating isoenzymes specific assessment [36, 37].

In adults, midazolam is metabolized rapidly [7]; the recovery of unchanged midazolam in urine of adult subjects is $1 \%$ [5] suggesting that metabolism is the main route of midazolam elimination in man. Midazolam is hydroxylated to form 1-hydroxymidazolam by hepatic CYP3A4 [3, 3841] and by CYP3A5 [38, 40-43]. The oxidative metabolism of midazolam is an aliphatic hydroxylation [38]. A significant correlation was observed between the fraction of 1hydroxymidazolam excreted into urine and the postconceptional age [10].

Plasma $\mathrm{Cl}$ of midazolam is widely used as an in vivo surrogate measurement of CYP3A4 and CYP3A5 activities $[44,45]$. $\mathrm{Cl}$ of midazolam is lower in preterm infants than in older children and adults [2]. The percent recovery of midazolam into the urine is higher in infants $(0.44 \%)$ than in adults $(0.14 \%)$, confirming that the metabolic rate of midazolam is reduced in infants. CYP3A4 activity surges in the liver during the first week of life $[8,9]$. Therefore, the expression of CYP3A4 in the neonatal liver is lower than that in the adult. CYP3A5 expression shows large interindividual variability and has been detected in only $10 \%$ to $30 \%$ of neonate liver samples tested [11].

Ince et al. [46] developed a novel maturation function for midazolam $\mathrm{Cl}$ based on studies in premature neonates, infants, toddlers, children, adolescents, and adults. This model provides a quantitative insight in the development pattern of in vivo CYP3A activities across the pediatric range, including premature neonates. The largest change in $\mathrm{Cl}$ of midazolam, which is metabolised by CYP3A4/5 in vivo and in vitro, appears in the first week of life [40]. Ince et al. [46] studied the interactions of hepatic CYP3A activity using midazolam as an in vivo probe. The effect of ontogeny on intestinal CYP3A activity is still unknown; intestinal CYP3A is of considerable importance. The knowledge of the maturation of CYP3A mediated first pass elimination of midazolam is important to understand the contribution of the intestine to the liver to the first-pass elimination of midazolam.

The ontogeny of midazolam glucuronidation was studied in 22 preterm infants [10]. Midazolam $(100 \mu \mathrm{g} / \mathrm{kg})$ was administered intravenously $(n=15)$ or orally $(n=7)$. After intravenous administration, the median percentage of the dose excreted into the urine, over 6-hour intervals, was $0.44 \%$ (midazolam), 0.04\% (1-hydroxymidazolam), and 1.57\% (1hydroxymidazolam glucuronide). After oral administration, the median percentage of the dose excreted into the urine was $0.11 \%$ (midazolam), $0.02 \%$ (1-hydroxymidazolam), and $1.69 \%$ (1-hydroxymidazolam glucuronide). The glucuronidation of 1-hydroxymidazolam is immature in preterm infants less than 2 weeks of postnatal age.

\subsection{Pharmacokinetics of Midazolam in Neonates and Chil-} dren. The $\mathrm{Cl}$ of midazolam was measured in 24 preterm infants and the mean was $1.8(\mathrm{~mL} / \mathrm{kg}$ per $\mathrm{min})$ [26]. In children with age $>2$ years, the $\mathrm{Cl}$ of midazolam was $9.6 \pm$ $3.5 \mathrm{~mL} / \mathrm{kg}$ per $\mathrm{min}$ (range: 5.8 to $13.6 \mathrm{~mL} / \mathrm{kg} / \mathrm{min}$ ) [17, 47] and $6.6 \mathrm{~mL} / \mathrm{kg}$ per min in adults [5]. The lower $\mathrm{Cl}$ of midazolam observed in neonates is due to the lower expression of CYP3A4 and CYP3A5 in neonatal liver [9, 11, 48, 49].

The published literature on the pharmacokinetics of midazolam in neonates is scarce and the available information is heterogeneous because the work was done in healthy neonates [26], in critically ill infants [2, 6, 27-29], or in infants undergoing extracorporeal membrane oxygenation (ECMO) $[30,31]$.

The information on the pharmacokinetics of midazolam summarised in this review is organised on the neonate health status, and it is reported in (a) healthy neonates, (b) in critically ill neonates (c), and in infants undergoing extracorporeal membrane oxygenation (ECMO) and finally (d) the population pharmacokinetics of midazolam are reviewed in neonates. The pharmacokinetic parameters of midazolam are summarised in Table 1.

3.4. Pharmacokinetics of Midazolam in Healthy Neonates. The pharmacokinetics of intravenous midazolam $(100 \mu \mathrm{g} / \mathrm{kg})$ were studied in 24 healthy preterm infants, with a gestational age between 26 and 34 weeks [26]. The maximal concentration of midazolam in plasma (Cmax) and the time to reach Cmax (Tmax) were $108 \mathrm{ng} / \mathrm{mL}$ (range: 48.8 to $217 \mathrm{ng} / \mathrm{mL}$ ) and 0.5 hours (range: 0.5 to 4.0 hours), respectively. For midazolam, $t_{1 / 2}$ was 6.3 hours (range: 2.6 to 17.7 hours), $\mathrm{Cl}$ was $1.8 \mathrm{~mL} / \mathrm{kg}$ per $\mathrm{min}$ (range 0.7 to $6.7 \mathrm{~mL} / \mathrm{kg}$ per $\mathrm{min}$ ), Vd was $1.1 \mathrm{~L} / \mathrm{kg}$ (range: 0.4 to $4.2 \mathrm{~L} / \mathrm{kg}$ ), and $\mathrm{AUC}_{0--\infty}$ was $971 \mathrm{ng} \cdot \mathrm{h} / \mathrm{mL}$ (range: 248 to $2353 \mathrm{ng} \cdot \mathrm{h} / \mathrm{mL}$ ). In the text, these values are referred to as the "normal values" or the "normal estimates." 


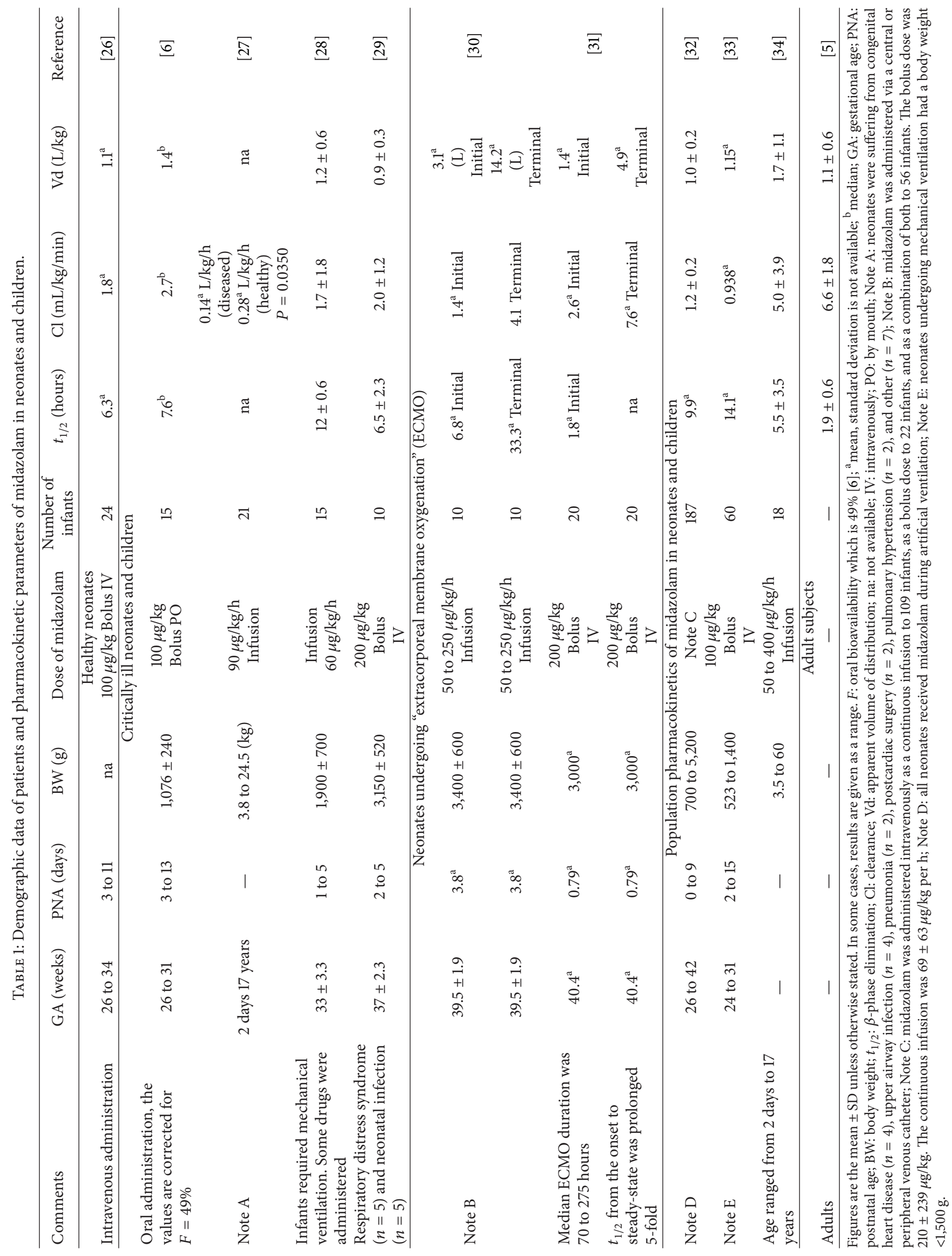


No significant relationships were detected between age (gestational, postnatal, or postconceptional) and midazolam $\mathrm{Cl}, \mathrm{Vd}$, and $t_{1 / 2}$. For 1-hydroxymidazolam, Cmax was $8.2 \mathrm{ng} / \mathrm{mL}$ (range: $<0.5$ to $68.2 \mathrm{ng} / \mathrm{mL}$ ) and Tmax was 6 hours (range: 1 to 12 hours). The median 1-hydroxymidazolam $\mathrm{AUC}_{0-t}$ to midazolam $\mathrm{AUC}_{0-t}$ ratio was low (0.09) and showed a large interindividual variation (range: $<0.001$ to 1 ). There were no relationships between 1-hydroxymidazolam pharmacokinetic parameters and midazolam Cmax, AUC, and $t_{1 / 2}$. No 4-hydroxymidazolam could be detected.

Anderson and Larsson [50] described a maturation model for midazolam $\mathrm{Cl}$ in neonates and children. $\mathrm{Cl}$ maturation, standardized to a $70 \mathrm{~kg}$ person, was described using the Hill equation. Mature $\mathrm{Cl}$ was 523 (CV32\%) $\mathrm{mL} / \mathrm{min}$ per $70 \mathrm{~kg}$. The maturation $t_{1 / 2}$ was 73.6 weeks. Predicted $\mathrm{Cl}$ changes with age, based on this model, were in close agreement with physiologically based pharmacokinetic models. Previously published pharmacokinetic parameters can be used to develop maturation models that address gaps in current knowledge regarding the influence of age on a drug's disposition. If midazolam sedation target concentration of $100 \mathrm{ng} / \mathrm{mL}$, similar to that given to adults, is assumed, we might anticipate steady-state infusion rates of $14 \mu \mathrm{g} / \mathrm{kg}$ per hour in neonates, $50 \mu \mathrm{g} / \mathrm{kg}$ per hour in a 1-year-old infant, $60 \mu \mathrm{g} / \mathrm{kg}$ per hour in a 5 -year-old infant, and $50 \mu \mathrm{g} / \mathrm{kg}$ per hour in a 12-year-old child. Age-related pharmacodynamic differences that will affect dose and the impact of active metabolites on response have not yet been quantified.

\subsection{Pharmacokinetics of Midazolam in Critically Ill Neonates} and Children. Disease reduces the midazolam elimination rate in neonates. In critically ill neonates, undergoing mechanical ventilation, $t_{1 / 2}$ was 9.8 hours, after a $200 \mu \mathrm{g} / \mathrm{kg}$ bolus of midazolam, and 12 hours, after a constant infusion of $60 \mu \mathrm{g} / \mathrm{kg}$ per hour of midazolam [28]. In normal values $t_{1 / 2}$ is 6.3 hours. These estimates are $155 \%$ and $190 \%$, respectively, of the normal values [26].

A 15.1-year-old girl, suffering from renal failure, with malignant hypertension and with a creatinine concentration of $691 \mu \mathrm{mol} / \mathrm{L}$, received an intravenous bolus of $100 \mu \mathrm{g} / \mathrm{kg}$ midazolam. $t_{1 / 2}, \mathrm{Cl}$, and $\mathrm{Vd}$ of midazolam of this girl were 6.3fold longer, 2.6-fold greater, and 14.5-fold larger, respectively, [34] than the normal values [26]. The patient's mean of 1hydroxymidazolam plus 1-hydroxymidazolam glucuronide was more than 3 times above the population value [34].

A 1.1-year-old boy, suffering from pneumonia, received the CYP3A4 inhibitor erythromycin and the CYP3A4 substrate fentanyl. He had a $t_{1 / 2}$ and a $\mathrm{Cl}$ of midazolam of 3.8-fold longer and 1.8-fold greater, respectively, [34] than the normal values [26].

Vet et al. [27] determined the effects of inflammation and disease severity on midazolam pharmacokinetics and pharmacodynamics in 21 critically ill children aged between 2 days and 17 years. Midazolam continuous infusion was $90 \mu \mathrm{g} / \mathrm{kg}$ per hour (range: 50 to $270 \mu \mathrm{g} / \mathrm{kg}$ per hour). The pharmacokinetic parameters of midazolam are summarised in Table 1 . Eleven severely critically ill 2.5 -year-old patients (range: 0.1 to 9.0 years) needed midazolam for sedation.
They were suffering from congenital heart disease, upper airway infection, pneumonia, postcardiac surgery and pulmonary hypertension, and other diseases. Midazolam $\mathrm{Cl}$ was significantly lower in these children (median $=0.14 \mathrm{~L} / \mathrm{kg}$ per hour) than in 10 patients with less severe disease; their median $\mathrm{Cl}$ was $0.28 \mathrm{~L} / \mathrm{kg}$ per $(P=0.035)$. A significant negative correlation was found between disease severity and midazolam $\mathrm{Cl}$ corrected for body weight $(r=-0.49 ; P=$ $0.02)$. These results suggest that increased disease severity is associated with reduced midazolam $\mathrm{Cl}$. Likely, these results reflect a reduction of CYP3A activity.

Alternative explanations could be the altered protein binding, midazolam being highly bound to plasma proteins (98\% in adults, [5]), or, less likely, reduced blood flow, because midazolam has an intermediate extraction rate [51].

The pharmacokinetics of midazolam was studied in 15 preterm infants undergoing mechanical ventilation for respiratory distress syndrome [28]. Midazolam was administered as an intravenous continuous infusion of $60 \mu \mathrm{g} / \mathrm{kg}$ per hour; the infusion lasted for $60.0 \pm 23.3$ hours. In these patients, $t_{1 / 2}$ estimate was double the normal value [26]. Hypotension, associated with a slight reduction of heart rate, was observed in 4 cases after midazolam administration [28]. Mean systolic and diastolic blood pressure fell from 59/40 to $35 / 25 \mathrm{~mm} \mathrm{Hg}$. In 3 infants, the hypotension occurred immediately after the administration of midazolam bolus dose. In these three infants, the midazolam plasma concentrations were $0.17,0.58$, and $1.24 \mu \mathrm{g} / \mathrm{mL}$; in two cases, the patients received fentanyl before midazolam. The metabolic ratio of midazolam to 1hydroxymidazolam, was $16.1 \pm 21.2(n=11)$ at 48 hours after the administration. Various drugs were coadministered with midazolam during the study; they were fentanyl $(n=7)$, antibiotics, in most cases betalactams and aminoglycosides $(n=13)$, albumin $(n=5)$, and vasopressin drugs $(n=$ 3). Jacqz-Aigrain et al. [28] conclude that the elimination of midazolam was markedly delayed in premature infants with respiratory distress syndrome undergoing mechanical ventilation. However, these authors did not take into consideration the possible effects of the drugs coadministered with midazolam. In particular, fentanyl, a substrate for CYP3A4 [52], can inhibit the metabolism of midazolam increasing its $t_{1 / 2}$.

Ten critically ill preterm infants, with a postnatal age of 2 to 5 days, received a single intravenous bolus dose of $200 \mu \mathrm{g} / \mathrm{kg}$ of midazolam [29]. Midazolam was well tolerated during and after the intravenous administration. There was no clinical evidence of any adverse effects after midazolam administration, and the heart rate and the arterial blood pressure remained unchanged during the study. $t_{1 / 2}, \mathrm{Cl}$, and Vd were $6.5 \pm 2.3$ hours, $2.0 \pm 1.2 \mathrm{~mL} / \mathrm{kg}$ per min, and $0.9 \pm$ $0.3 \mathrm{~L} / \mathrm{kg}$, respectively. The kinetic parameters in these infants were similar to those of normal values [26].

Ince et al. [43] performed a population pharmacokinetic modelling using a joint dataset of 3 studies. Fifty-four children, aged between 1 month and 17 years, who received intravenous midazolam (bolus and/or continuous infusion) for sedation were enrolled in the study. The parameter 
estimates from the final model were used for simulation and to predict the concentrations from the following midazolam schedules (intravenous bolus of $100 \mu \mathrm{g} / \mathrm{kg}$ followed by an intravenous infusion of either $50 \mu \mathrm{g} / \mathrm{kg}$ per hour, for postoperative monitoring, or $100 \mu \mathrm{g} / \mathrm{kg}$ per hour for conscious sedation). In children, a large variability in the pharmacokinetic parameters of midazolam was observed. Midazolam is a substrate for CYP3A4 and CYP3A5 and the expression of these enzymes considerably varies in neonates $[6,10,11]$.

The wide variability of midazolam pharmacokinetic parameters cannot be explained by age-related changes alone. Ince et al. [43] studied these age-related changes in relation to other covariates to explain the variability in the pharmacokinetics of midazolam. The following covariates were tested for all parameters: bodyweight, postnatal age, specific subpopulation, and mechanical ventilation (yes/no). Midazolam, 1-hydroxymidazolam, and 1-hydroxymidazolam glucuronide concentrations were considered to determine the pharmacokinetics of midazolam and metabolites using NONMEN 6.2. A SimCYP pediatric simulator was used for simulation. A reduction of $93 \%$ for CYP3A4/5 (midazolam to 1-hydroxymidazolam) and $86 \%$ for uridine diphosphate glucuronosyltransferase (1-hydroxymidazolam to 1hydroxymidazolam glucuronide) mediated $\mathrm{Cl}$ was found in pediatric intensive care patients compared with the other 2 patient groups. Ince et al. [43] did not find a significant influence of age or body weight on CYP3A4/5 mediated total $\mathrm{Cl}$. For uridine diphosphate glucuronosyltransferase mediated $\mathrm{Cl}$, body weight explained $41.5 \%$ of the variability. From infancy to adolescence, critical illness seems to be the major determinant of midazolam $\mathrm{Cl}$, which may result from reduced CYP3A4/5 activity due to inflammation. This may have important implications for dosing of midazolam and other CYP3A drug substrates in critically ill children.

A new dosing schedule was designed, aiming for midazolam concentrations between 45 and $64 \mathrm{ng} / \mathrm{mL}$ for postoperative monitoring after procedural sedation [53] and between 205 and $307 \mathrm{ng} / \mathrm{mL}$ for conscious sedation in "neonatal intensive care unit" patients [54]. These concentrations correspond with previously reported adequate sedation levels of the respective population groups and are used for indicative purposes only.

3.6. Pharmacokinetics of Midazolam in Neonates Undergoing Extracorporeal Membrane Oxygenation (ECMO). Extracorporeal membrane oxygenation (ECMO) is a form of prolonged cardiopulmonary bypass used to support patients with life-threatening respiratory or cardiac failure [55]. In neonates, ECMO is used for a variety of indications, including sepsis and pulmonary disease such as meconium aspiration syndrome, persistent pulmonary hypertension, or congenital hernia [55].

ECMO yields variability and lack of predictability in drug behaviour. The most common mechanisms by which ECMO affects pharmacokinetics are sequestration of the drug in the circuit and the increase of drug $\mathrm{Cl}$ and $\mathrm{Vd}[55,56]$. The pharmacokinetic parameters of drugs undergoing ECMO vary during this therapy. Thus, Table 1 gives two values for each pharmacokinetic parameter, an estimate was obtained at the start, and another one was obtained at the end of ECMO therapy.

Adequate sedation of neonates receiving ECMO is essential to allay the physical, emotional, and psychologic distress experienced during intensive care. Midazolam, a short-acting benzodiazepine derivative with rapid onset of action, is the sedative of choice and is preferred over other benzodiazepines because of its water solubility and the perceived rapid elimination [30].

Twenty neonates with gestational age of $39.5 \pm 1.9$ weeks, postnatal age of 3.8 days, and body weight of $3,400 \pm$ $600 \mathrm{~g}$ were enrolled in the study [30]. The infants were randomized into two groups: group $1(n=10)$ received midazolam extracorporeally (into the circuit), via a pigtail catheter, whereas group $2(n=10)$ received the drug via a central or peripheral venous catheter. Midazolam was administered as a continuous infusion at a rate between 50 and $250 \mu \mathrm{g} / \mathrm{kg}$ per hour, initiated as soon as cannulation was achieved and extracorporeal blood flow was established. The pharmacokinetic parameters obtained by Mulla et al. [30] are summarised in Table 1.

The mean metabolic ratio was of 1-hydroxymidazolam to midazolam 0.17 (range: 0.03 to 0.9 ) and appeared to be significantly higher than that previously reported in nonECMO infants (0.09), and it was similar to those observed in older children and adults (range: 0.13 to $0.25[57,58]$ ).

DeBerry et al. [59] determined the general practice guideline used for pain and anxiolytic pharmacotherapy of pediatric patients at ECMO centers. Fentanyl was the most commonly used drug for pain medication and continuous infusion. However, midazolam was considered to be the most effective agent used.

Ahsman et al. [31] studied 20 neonates undergoing ECMO. The median gestational age, postnatal age, and bodyweight were 40.4 weeks, 0.79 days, and 3,000 g, respectively. Midazolam $(200 \mu \mathrm{g} / \mathrm{kg})$ was administered by a venoarterial catheter as a bolus infusion before cannulation. The median ECMO duration was 124 hours (range: 70 to 275 hours). When discomfort occurred, midazolam was started as a continuous infusion of $100 \mu \mathrm{g} / \mathrm{kg}$ per hour. The midazolam dose was incrementally adjusted (with steps of $100 \mu \mathrm{g} / \mathrm{kg}$ per hour) on the basis of the required level of sedation, which was objectified with the validated COMFORT behaviour scale. Once the patient was fully sedated, the midazolam infusion was interrupted until COMFORT scores indicated that additional sedation was necessary.

Midazolam $\mathrm{Cl}$ and $\mathrm{Vd}$ rapidly increased in 5 days of ECMO therapy. The kinetic parameters of midazolam are summarised in Table 1. In contrast, the Vd estimates for 1-hydroxymidazolam and 1-hydroxymidazolam glucuronide remained constant at $10.2 \mathrm{~L}$ and $1.2 \mathrm{~L}$, respectively.

To quickly reach stable serum concentrations of $400 \mathrm{ng} / \mathrm{mL}$, the optimal dose regimen would be a continuous infusion of $300 \mu \mathrm{g} / \mathrm{kg}$ per hour for the first 6 hours, after which, the infusion rate should be reduced to $150 \mu \mathrm{g} / \mathrm{kg}$ per hour. After 5 days, the infusion rate should be increased to $200 \mu \mathrm{g} / \mathrm{kg}$ per hour to compensate for the continual 
increasing of midazolam $\mathrm{Cl}$ and 1-hydroxymidazolam $\mathrm{Cl}$. 1-Hydroxymidazolam glucuronide accumulated during ECMO, providing an increased proportion of the overall effect, up to $34 \%$ after 7 days of ECMO therapy. Large unexplained interindividual variability warrants careful titration of sedation effects. Ahsman et al. [31] did not find any effect of serum creatinine on pharmacokinetic parameters. The use of creatinine as a marker of renal function in newborn infants is in dispute $[60,61]$.

\subsection{Population Pharmacokinetics of Midazolam in Neonates} and Children. In literature there are three studies of midazolam population pharmacokinetics [32-34]. One hundred and eighty-seven neonates, requiring intravenous sedation for mechanical ventilation, were enrolled in the study [32]. Their gestational and postnatal ages ranged from 26 to 42 weeks of amenorrhea and from 0 to 9 days, respectively. The birthweight ranged from 700 to 5,200 g. Midazolam was administered intravenously as a continuous infusion of $69 \pm$ $93 \mu \mathrm{g} / \mathrm{kg}$ per hour (range: 11 to $603 \mu \mathrm{g} / \mathrm{kg}$ per hour) to 109 infants; the infusion lasted for 6 to 171 hours (62 \pm 31 hours). A bolus dose of $210 \pm 239 \mu \mathrm{g} / \mathrm{kg}$ (range: 32 to $1,600 \mu \mathrm{g} / \mathrm{kg}$ ) was administered to 22 infants, and a combination of both was administered to 56 neonates. The mean midazolam doses required for critically ill neonates are lower than those required for wealthy neonates. Mean $t_{1 / 2}$ was 9.9 hours, $\mathrm{Cl}$ was $1.2 \pm 0.2 \mathrm{~mL} / \mathrm{min} / \mathrm{kg}$, and $\mathrm{Vd}$ was $1.0 \pm 0.2 \mathrm{~L} / \mathrm{kg}$ [32]. There was a large interindividual variability in the $\mathrm{Cl}(\mathrm{CV}, 17 \%)$ and Vd (CV, 20\%). Compared with the population estimate, $\mathrm{Cl}$ was 1.6 times higher in neonates with a gestational age of more than 39 weeks and was 0.7 -fold lower in neonates receiving inotropic support. The postnatal age had no apparent effect on midazolam pharmacokinetics. The estimates of the population pharmacokinetic parameters and their interindividual coefficients of variation $(\mathrm{CV})$ without covariates were $\mathrm{Cl}=$ $0.107 \mathrm{~L} / \mathrm{kg}(\mathrm{CV}, 83 \%), \mathrm{Vc}$ (central volume) $=0.788 \mathrm{~L}(\mathrm{CV}$, $92 \%)$, and $\mathrm{Vp}$ (peripheral volume) $=0.969 \mathrm{~L}(\mathrm{CV}, 163 \%)$. Birthweight was clearly correlated with $\mathrm{Cl}$ and $\mathrm{Vc}$ and, to a lesser extent, with $\mathrm{Vp}$. The authors did not give the level of significance of these correlations. The gestational age correlated with the birthweight $(r=0.89 ; P=0.0001)$. The 531 measured plasma concentrations of midazolam ranged from 0 to 7,100 ng/mL; 105 samples were above $1,000 \mathrm{ng} / \mathrm{mL}$. Midazolam was not detected in 19 samples. Aminoglycosides, aminopenicillins, and third generation cephalosporins increased the plasma midazolam concentrations for $73.8 \%$, $72.2 \%$, and $48.7 \%$, respectively. Aminoglycoside treatment was associated with a $50 \%$ decrease in midazolam $\mathrm{Cl}$.

Lee et al. [33] studied the population pharmacokinetics in 60 premature infants undergoing mechanical ventilation. Their mean gestational age was 27 weeks (range: 24 to 31 weeks), their postnatal age was 4.5 days (range: 2 to 15 days), and their body weight was $965 \mathrm{~g}$ (range: 523 to $1,470 \mathrm{~g}$ ). A rapid intravenous bolus of $100 \mu \mathrm{g} / \mathrm{kg}$ was administered every 4 to 6 hours. Average parameter values for infants with birthweight of $1,000 \mathrm{~g}$ were as follows. Systemic $\mathrm{Cl}$ was $0.783 \mathrm{~mL} / \mathrm{min}(\mathrm{CV}=83 \%)$ and $\mathrm{Vd}$ of central comportment was $473 \mathrm{~mL}(\mathrm{CV}=70 \%) \cdot t_{1 / 2}$ was not given. For infants with body weight more than $1,000 \mathrm{~g}, \mathrm{Cl}$ was $1.24 \mathrm{~mL} / \mathrm{min}$ $(\mathrm{CV}=78 \%)$ and $\mathrm{Vd}$ was $823 \mathrm{~mL}(\mathrm{CV}=43 \%)$. The average population $\mathrm{Cl}$ in boys $(0.642 \mathrm{~mL} / \mathrm{min})$ was less than in girls $(0.808 \mathrm{~mL} / \mathrm{min})$. The level of significance of this difference was not given. The population mean $\mathrm{Cl}$ of overall patients was $0.938 \mathrm{~mL} / \mathrm{kg}$ per min. The average Vd of overall infants was $1.15 \mathrm{~L} / \mathrm{kg}$, which agreed closely with the $\mathrm{Vd}$ of $1.0 \mathrm{~L} / \mathrm{kg}$ in term and preterm infants [32].

The population kinetics of midazolam was studied in eighteen pediatric patients, aged from 2 days to 17 years [34]. Midazolam was administered as an intravenous bolus of $100 \mu \mathrm{g} / \mathrm{mL}$ followed by a continuous infusion ranging from 50 to $400 \mu \mathrm{g} / \mathrm{kg}$ per hour, for 3.8 hours to 25 days for conscious sedation. $t_{1 / 2}, \mathrm{Cl}$, and $\mathrm{Vd}$ of midazolam were $5.5 \pm 3.5$ hours, $5.0 \pm 3.9 \mathrm{~mL} / \mathrm{kg}$ per $\mathrm{min}$, and $1.7 \pm 1.1 \mathrm{~L} / \mathrm{kg}$, respectively. Half of the patients had an age less than 6 months [34]. Mean $\mathrm{Cl}$ rate is lower than that reported in patients with age greater than 2 years (mean $\pm \mathrm{SD}=9.6 \pm 3.5 \mathrm{~mL} / \mathrm{kg}$ per $\min [61,62]$ ).

The $\mathrm{Cl}$ reported by de Wildt et al. [34] is comparable to that obtained in another study performed with pediatric intensive care patients, aged between 26 days and 5 years (mean $\pm \mathrm{SD}=5.8 \pm 3.8 \mathrm{~mL} / \mathrm{kg}$ per min [17]), when studied during the first 24 to 48 hours of midazolam infusion. These data support an age-related increase of midazolam $\mathrm{Cl}$, consequent to an age-related surge in CYP3A4 and CYP3A5 activities [49].

1-Hydroxymidazolam to midazolam ratio (mean $\pm \mathrm{SD}=$ $0.21 \pm 0.20,[34])$ is in agreement with the ratio obtained in pediatric patients who received midazolam after cardiac surgery $($ mean \pm SEM $=0.25 \pm 0.03$ [59]). In contrast, the ratio obtained by Wildt et al. [34] was higher than that in newborn infants $<2$ weeks of age during continuous infusion of midazolam $(0.06 \pm 0.05[28])$.

3.8. Pharmacodynamics of Midazolam in Neonates. Very little is known about the pharmacodynamics of midazolam in infants and only two articles are available in literature $[54,63]$. Swart et al. [63] stated that from the clinical studies it is clear that there is a large variability in response to a given concentration of midazolam. Vet et al. [27] did not find a correlation between inflammation severity and COMFORT score. Trouiller et al. [64] and Arbor et al. [65] said that the optimal measure to monitor the pharmacodynamic endpoint still needs to be determined. Dosing regimens in children are based upon rather empirical extrapolations from the dosing regimens in adults. Several authors have developed scaling methods to predict midazolam $\mathrm{Cl}$ as a function of age, taking ontogeny into account [66-68]. From these data it can be concluded that body weight increases with age from approximately $0.06 \mathrm{~L} / \mathrm{kg}$ per hour in preterm neonates to $0.6 \mathrm{~L} / \mathrm{kg}$ per hour in children 5 years of age before decreasing to $0.4 \mathrm{~L} / \mathrm{kg}$ per hour in adult patients.

Twenty-one infants, aged from 2 days to 17 years, received a continuous infusion of midazolam from 50 to $400 \mu \mathrm{g} / \mathrm{kg}$ per hour, for a period of 3.8 hours to 25 days [54]. A possible pharmacokinetic-pharmacodynamic relationship for midazolam in pediatric intensive care patients and the determination of how adequate sedation could be reached 
using the COMFORT scale was studied. Sedation levels were determined using the COMFORT scale as well as the plasma concentrations of midazolam and metabolites. An evident pharmacokinetic-pharmacodynamic relationship was not found. In 20 of the 21 patients studied, midazolam dosing could be effectively titrated to the desired level of sedation, assessed by the COMFORT scale. Based on these findings, there is no relationship between pharmacodynamic parameters and pharmacodynamic outcome. De Wildt et al. [54] recommend that midazolam dosing should be titrated according to the desired clinical effect combination with a validated assessment instrument such as the COMFORT scale. The COMFORT scale rates 6 behavioural and 2 physiologic dimensions of distress, each scored on a subscale from 1 to 5 . Thus, a maximum score is considered reflective of oversedation, between 17 and 26 as effective/optimal sedation, as proposed by Marx et al. [69]. As reflected by the Pediatric Risk of Mortality (PRISM) score, disease severity among our patients varied considerably. Seven patients required analgesia (morphine, codeine, fentanyl, and acetaminophen) during the midazolam infusion. No significant relationship between sedation level category and drug or metabolite concentrations was detected. The ranges of midazolam study (50 to $400 \mu \mathrm{g} / \mathrm{kg}$ per hour) were in agreement with other data from studies in pediatric intensive care patients $[70,71]$.

3.9. Sedation of Neonates and Children by Midazolam. Neonates can perceive pain when mechanically ventilated: this fact has been demonstrated by the physiological, biochemical, and behavioural changes indicative of pain and stress in newborn infants during mechanical ventilation [72]. Pain induces agitation in the newborn, and the newborn's agitation may contribute to asynchrony between the newborn and the ventilator. To sedate neonates with midazolam this drug is usually given intravenously or by intranasal administration. The oral administration of midazolam in neonates is little used and, in literature, only two articles on oral midazolam in neonates are available $[2,6]$. No data of sublingual administration of midazolam in neonates was found in literature.

D. A. Rosen and K. R. Rosen [73] wrote a review on the sedation with midazolam in conscious pediatric patients. These authors stated that the advantages of midazolam include quick onset and short duration of action and hemodynamic stability which may be associated with improved patient acceptance. The comparison with diazepam showed that midazolam has a more controlled sedation, with a quicker recovery time. Midazolam yields a shorter recovery and less vomiting than diazepam in children who underwent surgery. The safety and tolerability profile of midazolam in pediatric patients is comparable or superior to that observed in adults. Patients who are haemodynamically unstable, as well as preterm and term infants, are at greater risk of hypotension while receiving sedation. Midazolam provides an important additional option for providing intravenous conscious sedation in the pediatric population.

The American Academy of Pediatrics Committee on Drugs has issued guidelines categorizing pharmacological intervention into three levels: conscious sedation, deep sedation, and general anaesthesia [74]. Conscious sedation refers to a state of depressed consciousness that "allows protective reflexes to be maintained" and "permits appropriate responses by the patient to physical stimuli or verbal commands." Deep sedation is defined in part as "partial or complete loss of protective reflexes" and lack of purposeful response to physical stimulation. Deep sedation requires the presence of personnel skilled in airway management and cardiopulmonary resuscitation [20].

Intravenous infusion of benzodiazepines is important to assist ventilation and other potentially distressing procedures. Combined with intermittent or continuous infusion with opioids, the benzodiazepines provide smooth control of anxiety, pain, and agitation [75]. The major adverse effects of long-term benzodiazepine infusion are withdrawal symptoms and delayed awakening. Intravenous midazolam represents an important choice among drugs used for sedation in the "neonatal intensive care unit" for short-term use in infants undergoing assisted ventilation and generally rapid awakening when the drug is discontinued [76]. Midazolam and lorazepam are the most frequently employed benzodiazepines in the "neonatal intensive care unit." These two drugs are distinguished from the other benzodiazepines by their relatively higher water solubility, rapid onset, and short duration of action [47]. These pharmacologic properties of midazolam facilitate regulation of the level of sedation. Midazolam is usually given by continuous infusion, following a loading dose.

Treluyer et al. [77] determined the minimal effective dose of intravenous midazolam required for appropriate sedation in $95 \%$ of patients, 1 hour after drug administration. Twentythree newborn infants, hospitalized in intensive care unit, were enrolled in the study. Their gestational age was $>33$ weeks and midazolam was administered as an intravenous bolus at a dose from 75 to $200 \mu \mathrm{g} / \mathrm{kg}$ followed by a maintenance dose ranging from 37.5 to $100 \mu \mathrm{g} / \mathrm{kg}$ per hour over 47 hours. The sedation procedure was classified as a success if all the following clinical criteria were met: no agitation, no grimacing, and no crying facial expression before as well as during tracheal suctioning. The estimated success probability, updated after each patient, was $<95 \%$ for all dose levels and led to allocation of the maximum loading dose $(200 \mu \mathrm{g} / \mathrm{kg})$. Based on the 23 patients studied, the final estimated probability of success was $76.9 \%$ (95\% credibility interval was 56.6 to $91.4 \%$ ) for the $200 \mu \mathrm{g} / \mathrm{kg}$ loading dose. The posterior success probability for the six doses $75,100,125,150,175$, and $200 \mu \mathrm{g} / \mathrm{kg}$ corresponded to $27.7 \%, 32.7 \%, 38.1 \%, 47.3 \%$, $52.5 \%$, and $76.9 \%$, respectively. Failures were recorded in 5 (25\%) of 20 patients receiving a $200 \mu \mathrm{g} / \mathrm{kg}$ midazolam loading dose. No significant effect of sedation on pulse oximetry, oxygenation index, or triggering of ventilator breathing was evident after the onset of midazolam administration. No significant adverse effects were observed. Pneumothorax was reported in two children who had received a $200 \mu \mathrm{g} / \mathrm{kg}$ initial loading dose and were classified as "success" for sedation. A decrease of more than $30 \%$ for systolic, diastolic, and mean blood pressure was observed during the study inclusion in none, two $(8.7 \%)$, and one $(4.3 \%)$ children, respectively (all received the $200 \mu \mathrm{g} / \mathrm{kg}$ loading dose of midazolam). 
Forty-six infants undergoing mechanical ventilation for respiratory distress syndrome were randomly assigned to receive midazolam $(n=24)$ or placebo $(n=22)$ as a continuous infusion [16]. Jacqz-Aigrain et al. [16] performed a prospective placebo controlled study of the effects of midazolam on hemodynamic variables and sedation as judged by a five-item behaviour score. Doses of midazolam were calculated to obtain plasma concentrations between 200 and $1000 \mathrm{ng} / \mathrm{mL}$ within 24 hours of starting treatment and to maintain these values throughout the study. In the treatment group, infants of 33-week gestation or more received a continuous infusion of $60 \mu \mathrm{g} / \mathrm{kg}$ per hour of midazolam. Infants below 33-week gestation received the same continuous infusion of $60 \mu \mathrm{g} / \mathrm{kg}$ per hour during the first 24 hours of treatment, followed by a continuous infusion of $30 \mu \mathrm{g} / \mathrm{kg}$ per hour of midazolam. The assigned treatment lasted for 5 days, but sedation with midazolam could be continued if prescribed by the attending neurologist. Midazolam gave a significantly better sedative effect than placebo $(P<0.05)$. Heart rate and blood pressure were reduced by treatment but remained within the normal range for gestational age and there was no effect on ventilatory indices. Hemodynamic instability requiring albumin and/or vasoactive drugs occurred in 14 infants, 8 of whom were in the midazolam group and 6 infants were in the placebo group. Intraventricular haemorrhage occurred in 8 infants in the midazolam group and 6 infants in the placebo group. Blood samples were obtained from 23 of 24 infants. Mean midazolam concentrations were $634 \pm$ $234 \mathrm{ng} / \mathrm{mL}, 628 \pm 327 \mathrm{ng} / \mathrm{mL}$, and $543 \pm 327 \mathrm{ng} / \mathrm{mL}$ at 24 and 48 hours and at the end of treatment, respectively. Substantial variability in plasma concentrations of midazolam was seen, but none of the infants had values below $200 \mathrm{ng} / \mathrm{mL}$ and only 2 infants (with a gestational age below 32 weeks) had a plasma concentration of midazolam above $1000 \mathrm{ng} / \mathrm{mL}$. There was no correlation between sedation score and corresponding midazolam concentration. No midazolam-related adverse effects were noted. Continuous infusion of midazolam at doses adapted to gestational age induces effective sedation in newborn infants on mechanical ventilation, with positive effects on hemodynamic variables. Midazolam was given over only a few days and the limited effects on heart rate and blood pressure that were reported should not encourage long-term administration.

Midazolam was administered as a continuous infusion at a dosage of 50 to $400 \mu \mathrm{g} / \mathrm{kg}$ per hour, to 24 infants, partly in combination with fentanyl ( 0.5 to $2.5 \mu \mathrm{g} / \mathrm{kg}$ per hour) for analgesia and sedation [17]. The mean duration of midazolam infusion was 11.6 days (range: 38 hours to 40 days). The efficiency of sedation in correlation with the midazolam concentration was evaluated by a clinical sedation score. Serum midazolam concentrations from 100 to $400 \mathrm{ng} / \mathrm{mL}$ were sufficient for sedation. Dosage had to be increased during therapy according to an increased midazolam $\mathrm{Cl}$. The evaluation of sedation score showed that sedation of artificially ventilated infants and young children can be established by continuous intravenous infusion of midazolam.

Arya and Ramji [19] performed a double blind randomized placebo controlled trial to determine the efficacy of midazolam as a sedative in mechanically ventilated newborn infants for 7 days. Seventeen neonates with a body weight $<2000 \mathrm{~g}$ received a bolus of midazolam of $200 \mu \mathrm{g} / \mathrm{kg}$ followed by continuous infusion of $60 \mu \mathrm{g} / \mathrm{kg}$ per hour. Sixteen infants received placebo. The midazolam group had significantly better sedation than the placebo group from 18 to 24 hours after enrollment. At 48 hours, there were no significant differences in sedation between midazolam and placebo groups. None of the infants had hypotension on loading midazolam. Sedation provided by continuous infusion of midazolam appeared to be comparable to morphine alone in newborn infants on mechanical ventilation. These authors observed that the behavioural assessment was used to demonstrate the sedative effect of midazolam in ventilated newborn infants. Opioid and benzodiazepines combination is most commonly used to sedate newborns, but their use is limited by prolonged variable elimination of these drugs, leading to prolonged sedation. Midazolam produces a rapid and consistent effect because of its short $t_{1 / 2}$. Hypotension has been reported as an adverse effect of midazolam in few infants after intravenous administration of midazolam [28, 78]. Arya and Ramji [19] did not find hypotension in any neonates.

When minimal sedation is required, intranasal midazolam is an excellent sedative [79]. Intranasal strategies have been introduced to maximize the potential for successful sedation and to minimize risk. These authors reviewed the literature to evaluate the effectiveness of a second dose of intranasal midazolam. The strategy incorporates a second dose of intranasal midazolam, 10 to $15 \mathrm{~min}$ after the first dose, to obtain the desired level of anxiolysis. One hundred infants with an age ranging from 1 to 59 months were enrolled in the study. Eighty patients (80\%) obtained satisfactory sedation effects. There were no reported complications, minimal untoward side reactions, and no delays in discharge. A second-dose of intranasal midazolam strategy was effective in achieving satisfactory minimal sedation in children. These authors stated that only a small proportion of patients would benefit from one dose of intranasal midazolam.

Intranasal midazolam use has been reported since 1988 [80]. The intranasal route is desirable because it obviates the need for intravenous access, avoids the pain of the intramuscular injection, and is easily accessible. Due to the reach vascular plexus of the nasal cavity and the communication to the subarachnoid space via the olfactory nerve and sheath, adequate cerebrospinal fluid levels can be achieved rapidly $[81,82]$. The bioavailability of intranasal midazolam ranged from $50 \%$ to $83 \%$ [83-85]. The most common adverse effects reported following intranasal midazolam are burning or irritation in the nose and a bitter taste in the mouth [86-88].

Intranasal midazolam was studied by Lane and Schunk [89] using a unique atomization delivery system. Two hundred and five children admitted to the study, aged from 1.5 to 60 months, had mean \pm SD age of $31.3 \pm 13.2$ months. The median initial dose of intranasal midazolam was $400 \mu \mathrm{g} / \mathrm{kg}$ (range: 300 to $800 \mu \mathrm{g} / \mathrm{kg}$ ). Laceration repair was the most common procedure necessitating sedation (89\%). Eleven patients $(5.4 \%)$ required an additional sedative dose to complete the procedure. Ten of 11 patients received ketamine as the adjunctive sedative, and 1 patient required additional intranasal midazolam. There was 1 adverse event (0.5\%). 
This was a minor desaturation episode following ketamine administration requiring a brief blow by oxygen. There were no adverse events in patients who received intranasal midazolam. These authors conclude that atomized intranasal midazolam is effective in providing anxiolysis to children undergoing minor procedures in the pediatric Department.

Harcke et al. [90] reviewed 162 consecutive sedations in which midazolam was employed. The patients' mean age was 4.1 years (range: 19 days to 19 years). Midazolam is effective in providing anxiolysis to children based upon a calculated dose of 200 to $400 \mu \mathrm{g} / \mathrm{kg}$. Intranasal midazolam has a rapid onset and is more convenient than intravenous agents, because of its short duration. A dose of $200 \mu \mathrm{g} / \mathrm{kg}$ is safe and effective. In 142 of 162 cases $(88 \%)$, midazolam demonstrated a positive effect; in 20 cases (12\%), it was ineffective. The adverse effects were brief coughing, sneezing, or crying often occurring immediately after midazolam administration, but these were not considered adverse reactions unless they persisted. In 91 of 162 cases $(56 \%)$, midazolam was used in conjunction with another agent. Fifteen adverse reactions (9\%) occurred, including delay in awakening in 4 patients, reactive airway in 2 cases, desaturation and apnea in 4 cases, seizure in 1 case, agitation in 2 cases, and vomiting in 2 cases. Midazolam was the sole sedative in 71 of $162(44 \%)$ cases. The use of midazolam to minimize the difficulty of starting an intravenous infusion constitutes the most common application. In $89 \%$ of the patients, it accomplished the desired effect. Of particular interest was the use of midazolam as a primary means of sedation since its intranasal route obviates the need for intravenous medication. An intranasally administered sedative with quick onset and short duration seems very innocuous.

3.10. Oral Administration of Midazolam in Neonates. Data describing midazolam disposition following oral administration to preterm infants are few. In literature, there are only two articles on the fate of midazolam following oral administration to neonates $[2,6]$. A single oral bolus dose of $100 \mu \mathrm{g} / \mathrm{kg}$ was administered to 15 preterm infants with gestational and postnatal ages ranging from 26 to 31 weeks and from 3 to 13 days, respectively. Mean \pm SD of body weight was $1076 \pm 240 \mathrm{~g}$. In 8 out of these 15 patients, the pharmacokinetics of intravenous midazolam was also studied. Apparent oral $\mathrm{Cl}$, apparent $\mathrm{Vd}$, and plasma $t_{1 / 2}$ are given as median and range. $\mathrm{Cl}$ was $2.7 \mathrm{~mL} / \mathrm{kg} / \mathrm{min}$ (range: 0.64 to $15.5 \mathrm{~mL} / \mathrm{kg} / \mathrm{min}$ ), $\mathrm{Vd}$ was $1.4 \mathrm{~L} / \mathrm{kg}$ (range: 0.3 to $12.1 \mathrm{~L} / \mathrm{kg}$ ), and $t_{1 / 2}$ was 7.6 hours (range: 1.2 to 15.1 ) hours. The absolute bioavailability was 0.49 (range: 0.12 to 1.0 ).

In another study, De Wildt et al. [2] evaluated the pharmacodynamics and safety of midazolam after intravenous continuous infusion or oral administration. Patients were randomly assigned to initially receive an oral bolus dose of $100 \mu \mathrm{g} / \mathrm{kg}$ midazolam. Pharmacodynamic measurements consisted of a COMFORT score at baseline and at $0.5,1$, 2, 4 and 6 hours after dose. A total of 24 infants were enrolled, of whom seven received both intravenous and oral midazolam, 13 infants received only intravenous midazolam, and 4 received only oral midazolam.
Overall, mean COMFORT score decreased (i.e., sedation increased) significantly within $30 \mathrm{~min}$ after intravenous administration and within 1 hour after oral administration $(P=0.003)$. No relationship was found between overall COMFORT scores or change in COMFORT score from baseline and midazolam. Diastolic blood pressure decreased significantly (approximately 11\%) after intravenous, but not after oral, midazolam administration. No serious adverse events were reported. Midazolam administered as an intravenous infusion or oral bolus dose appears to be effective and well tolerated in a small majority of preterm infants. However, a considerable number of neonates did not respond to midazolam. The lack of response may be due to the fact that patients truly experienced therapeutic failure and/or consequent to the inability of the COMFORT score to adequately reflect sedation uniformly in sick preterm infants.

3.11. Management of Refractory Seizures in Neonates by Midazolam. Slaughter et al. [91] reviewed the literature on the pharmacological treatment of neonatal seizures. Their research was based on 557 initial articles and 14 additional studies after reference reviews, with 16 meeting inclusion criteria. Seizures suspected in high-risk neonates require confirmation of seizures with electroencephalogram. If seizures are confirmed by electroencephalogram, give phenobarbital $20 \mathrm{mg} / \mathrm{kg}$ intravenously and start phenobarbital maintenance $5 \mathrm{mg} / \mathrm{kg}$ per day. If seizures continue give additional $20 \mathrm{mg} / \mathrm{kg}$ intravenously. If seizures continue there are three possible drugs to take into consideration: levetiracetam $(50 \mathrm{mg} / \mathrm{kg}$ intravenously, then $40 \mathrm{mg} / \mathrm{kg}$ per day maintenance, divided twice daily), phenytoin/fosphenytoin (20 mg/kg intravenously, and start a second maintenance medication, $5 \mathrm{mg} / \mathrm{kg}$ per day divided every 8 hours), or lidocaine $(2 \mathrm{mg} / \mathrm{kg}$ intravenously bolus, then $6 \mathrm{mg} / \mathrm{kg}$ per hour, then titrate down by $2 \mathrm{mg} / \mathrm{kg}$ per hour, every 12 hours). If seizures continue, administer midazolam $(0.15 \mathrm{mg} / \mathrm{kg}$ intravenous bolus, then $1 \mu \mathrm{g} / \mathrm{kg}$ per min, up to a maximum of $18 \mu \mathrm{g} / \mathrm{kg}$ per min). If seizures continue, consider phenobarbital drip or lidocaine drip if not yet tried (unless phenytoin/fosphenytoin has been used).

The neonatal period is one of the highest risk periods for seizures [92], which occurs in $1 \%$ to $5 \%$ of neonates [93] and is indicative of underlying neurologic dysfunction. Seizures are refractory to the first-line antiepileptic drugs, phenobarbital and phenytoin, in more than $50 \%$ of infants and children [94]. Midazolam succeeded to manage refractory neonatal seizures. In neonates, antiepileptic drugs can be even less effective in controlling seizures than in adults [95]. Little information is available on the use of midazolam in neonatal seizures. However, rapid control of status epilepticus with midazolam has been demonstrated with complete clinical and electrographic response in neonates who did not respond to phenobarbital and phenytoin $[23,24,96]$.

Van Roij et al. [97] reviewed the treatment of neonatal seizures. Midazolam has also been used for phenobarbital refractory seizures with an efficacy between $67 \%$ and $80 \%$. In other studies, midazolam was compared to lidocaine as a second-line anticonvulsive drug $[24,92,98,99]$. In a study 
by Shany et al. [98], four of the eight neonates treated with midazolam showed a partial response. Three neonates with status epilepticus did not respond to phenobarbital and phenytoin [92] but they responded to midazolam infusion. Midazolam was infused at a rate of 0.10 to $0.13 \mu \mathrm{g} / \mathrm{kg}$ per hour for a period of 43 to 54 hours. Midazolam may be considered a safe and effective antiepileptic drug in refractory neonatal seizures of diverse aetiologies.

Status epilepticus, a serious, life-threatening emergency, characterized by prolonged seizure activity, occurs most commonly in pediatric patients. Diazepam, phenytoin, or phenobarbital terminates seizures within 30 to $60 \mathrm{~min}$, but there are patients who are refractory to standard therapy. Midazolam has emerged as a new treatment option. The review by Holmes and Riviello [100] compared the use of midazolam with that of phenobarbital in published reports of pediatric patients refractory status epilepticus. Most of status epilepticus can be controlled by benzodiazepines, phenytoin, or phenobarbital; in refractory cases that persisted beyond this therapy, the potential treatment options are less than ideal. The antiepileptic properties of midazolam were identified during the late 1970s, and more recently the drug has emerged as an effective treatment for resistant status epilepticus. Midazolam was well tolerated by pediatric patients with refractory status epilepticus. In the study by Holmes and Rivielo [100], only one incidence of mild hypotension was present in a 4-week-old infant. A number of published case reports showed the successful use of midazolam in terminating refractory status epilepticus in a total of 29 pediatric patients [100]. Although midazolam has not been directly compared with pentobarbital in a controlled study, the antiepileptic effectiveness and apparent safety of midazolam in children warrant its consideration as the initial treatment in pediatric cases of refractory status epilepticus [100].

Castro Conde et al. [24] stated that the outcome of 45 neonates with electroencephalogram-confirmed seizures was analyzed with regard to treatment. Seizures persisted in 17 of 32 neonates receiving phenobarbital/phenytoin. Thirteen neonates had a poor outcome and 4 died. In contrast, seizures were rapidly controlled in 13 of 13 nonresponders to phenobarbital/phenytoin treated with midazolam $(0.15 \mathrm{mg} / \mathrm{kg}$ intravenous bolus, followed by continuous infusion of $1 \mu \mathrm{g} / \mathrm{kg}$ per min, increasing by 0.5 to $1 \mu \mathrm{g} / \mathrm{kg}$ per min every 2 min until a favourable response or a maximum of $18 \mu \mathrm{g} / \mathrm{kg}$ per min). If the status epilepticus persisted after the initial bolus, another bolus of 100 to $150 \mu \mathrm{g} / \mathrm{kg}$ was administered 15 to $30 \mathrm{~min}$ later. Nonresponders to phenobarbital/phenytoin were controlled by midazolam.

The efficacy of a combination of midazolam and phenytoin in treating generalized convulsive status epilepticus was studied in 122 children with the median age of 24.4 months (range: 0.5 to 197 months) [101]. Forty-three percent of patients required artificial ventilation. Thirty-two percent of patients developed respiratory insufficiency during initial therapy with midazolam. Three patients had an apnea, and 8 patients were intubated after a bolus of midazolam. Twentytwo percent of patients were artificially ventilated to protect the airway. No deaths were attributable to generalized convulsive status epilepticus itself. The treatment protocol consisted of a stepwise use of midazolam and phenytoin. Level 1: rectal midazolam of $500 \mu \mathrm{g} / \mathrm{kg}$, or $100 \mu \mathrm{g} / \mathrm{kg}$, intravenously was administered. Level 2: after $10 \mathrm{~min}, 20 \mathrm{mg} / \mathrm{kg}$ phenytoin was administered intravenously. Level 3: after phenytoin load, $200 \mu \mathrm{g} / \mathrm{kg}$ midazolam was administered intravenously as a bolus, followed by a continuous infusion of $100 \mu \mathrm{g} / \mathrm{kg}$ per hour of midazolam, increased by $100 \mu \mathrm{g} / \mathrm{kg}$ per hour every $10 \mathrm{~min}$, after extra loading of $100 \mu \mathrm{g} / \mathrm{kg}$, to a maximum of $1 \mathrm{mg} / \mathrm{kg}$ per hour. Level 4: phenobarbital $20 \mathrm{mg} / \mathrm{kg}$ intravenously, or pentobarbital 2 to $5 \mathrm{mg} / \mathrm{kg}$ intravenous load, 1 to $2 \mathrm{mg} / \mathrm{kg}$ per hour of phenobarbital was continuously intravenously infused. Eighty-two of 122 infants (68\%) received initial rectal diazepam. Cessation of epileptic activity was achieved with midazolam in 58 patients (48\%). Midazolam is an effective agent for seizure control [102]. Several studies in a small number of children have described the effective use of intravenous, intramuscular, rectal, nasal or sublingual midazolam [96, 102-104].

$\mathrm{Hu}$ et al. [23] determined the efficacy and safety of continuous midazolam infusion in neonates with uncontrollable neonatal seizures. Thirty-two neonates whose seizures could not be controlled by diazepam, phenytoins or phenobarbital were enrolled in the study. Midazolam was given as an intravenous bolus dose followed by a continuous infusion. The maximum infusion of midazolam ranged from 1 to $15 \mu \mathrm{g} / \mathrm{kg}$ per min, with an average of $4 \mu \mathrm{g} / \mathrm{kg}$ per min. There were no significant changes in serum sodium, potassium, calcium, or glucose in any of the patients. Four patients had recurrent seizures, which stopped after midazolam was reinstituted. Adverse effects included hypotension in 12 patients (38\%), that was successfully controlled with dopamine and/or dobutamine, and transient urinary retention in 38\% of infants. All the patients enrolled in the study had a successful management of seizures. These results suggest that midazolam is safe and effective for the treatment of uncontrollable seizures.

Midazolam is a highly effective antiepileptic agent, even in patients who have not responded to other benzodiazepines [102]. Compared with phenobarbital, midazolam has fewer hemodynamic consequences, minimizing the need for invasive monitoring. The need for endotracheal intubation and mechanical ventilation also appears to be less frequently necessary with midazolam. Patients recovery after midazolam is shorter than with phenobarbital. Although midazolam has not been directly compared with phenobarbital in a controlled study, the antiepileptic effectiveness and apparent safety of midazolam in children warrant its consideration as the initial treatment in pediatric cases of refractory status epilepticus.

Sheth et al. [96] studied six neonates with gestational and postnatal ages ranging from 30 to 41 weeks and 1 to 9 days, respectively. These neonates developed seizures from varying causes. In each case, seizures persisted for $>12$ hours despite high dose of phenobarbital with or without the addition of phenytoin. All infants received intravenously 20 to $40 \mathrm{mg} / \mathrm{kg}$ of phenobarbital. Maintenance phenobarbital dosage was approximately $8 \mathrm{mg} / \mathrm{kg}$ and was administered in two divided doses. Four of the six infants also received $20 \mathrm{mg} / \mathrm{kg}$ of phenytoin. Three infants were suffering from 
focal clonic seizures; two infants had tonic seizures and one had myoclonic seizures. Onset of the seizure was between 1 and 24 hours except in the patients with meningitis, in whom the onset was at 9 days. All infants received a standard intravenous loading dose of $20 \mathrm{mg} / \mathrm{kg}$ and subsequently an additional 20 to $40 \mathrm{mg} / \mathrm{kg}$ of phenobarbital. Maintenance phenobarbital dosage approximated $8 \mathrm{mg} / \mathrm{kg}$ and was administered in two divided doses. Four of the six infants also received $20 \mathrm{mg} / \mathrm{kg}$ of phenytoin. In all six infants, midazolam infusion was started with a loading dose of $150 \mu \mathrm{g} / \mathrm{kg}$ and then maintained between 100 and $400 \mu \mathrm{g} / \mathrm{kg}$ per hour. After the loading dose, clinical seizures were no longer observed in four infants. The remaining became seizure free within one hour after the administration of midazolam. These results show that midazolam administrated by continuous intravenous infusion may be a valuable adjunct in the management of refractory neonatal seizures.

\subsection{The Safety and Efficiency of Midazolam versus Diazepam} for the Treatment of Febrile Seizures in Children. McIntyre et al. [105] compared rectal diazepam and buccal midazolam for emergency room treatment in 177 children, who had a median age of 3 years, with acute febrile seizures. The dose of diazepam and midazolam ranged from 2.5 to $10 \mathrm{mg}$. The primary endpoint was the cessation of seizures within $10 \mathrm{~min}$ and for at least 1 hour, without respiratory depression requiring ventilation. The therapeutic success was $56 \%$ for buccal midazolam and $27 \%$ for rectal diazepam. The rate of respiratory depression did not differ between groups. Buccal midazolam was more effective than rectal diazepam for children presenting to hospital with acute febrile seizures and was not associated with increased incidence of repertory depression.

Mahmoudian and Zadeh [106] determined whether intranasal midazolam is as safe and effective as intravenous diazepam in the treatment of acute childhood seizures. Seventy children aged between 2 months and 15 years with acute febrile seizures were admitted to the "pediatric emergency department" of a general hospital. Intranasal midazolam $(0.2 \mathrm{mg} / \mathrm{kg})$ and intravenous diazepam $(0.2 \mathrm{mg} / \mathrm{kg})$ were administered after intravenous lines were established. Intranasal midazolam and intravenous diazepam were equally active. The main time to control seizures was $3.58 \pm 1.68 \mathrm{~min}$ (midazolam) and $2.94 \pm 2.62$ (diazepam). No significant side effects were observed in either groups. Although intranasal midazolam was as safe and effective as diazepam, seizures were controlled more quickly with intravenous diazepam than with intranasal midazolam.

3.13. Comparison of the Sedatives Effects of Midazolam with Those of Other Sedatives in Neonates. Many agents can depress the function of the central nervous system producing calming or drowsiness (sedation). Sedation may be performed with opioids (fentanyl, morphine, and diamorphine), with the sedative-hypnotic midazolam and with the aesthetic propofol in ventilated neonates.

Endotracheal intubation of premature infants is performed frequently in the "neonatal intensive care units" and delivery room. The procedure is associated with physiological and biochemical responses, and now there is strong evidence that premedication (sedation and analgesia) improves the physiological stability, decreases the difficulty of procedure, and also reduces the potential for airway injury [107].

Penido et al. [108] compared intubation conditions between midazolam and propofol in a blinded, randomized, and controlled study in 20 neonates. Ten patients, with a gestational age of $32 \pm 1.6$ weeks and with a bodyweight of $1653 \pm 357 \mathrm{~g}$, were treated with midazolam as an intravenous bolus of $200 \mu \mathrm{g} / \mathrm{kg}$ and $1 \mu \mathrm{g} / \mathrm{kg}$ remifentanil. The remaining 10 patients, with a gestational age of $31.5 \pm 1.5$ weeks and a body weight of $1523 \pm 35 \mathrm{~g}$, were treated with $2,000 \mu \mathrm{g} / \mathrm{kg}$ propofol and $1 \mu \mathrm{g} / \mathrm{kg}$ remifentanil. All neonates were in nasal continuous airway pressure therapy before intubation, with similar ventilatory parameters and degree of respiratory system. No statistical differences were observed as well between the drugs regarding pain and stress level before and after the intubation using the NIPS scale. No differences were observed in heart rate and blood pressure between the two drugs. Adverse effects such as hypotension were observed in two infants in each drug, and bradycardia was seen in one infant in the propofol group. The present findings did not show any difference in the quality of intubation, presence of adverse effects, changes on the hemodynamic variables, and quality of sedation and analgesia achieved when midazolam or propofol was used as a hypnotic associated with remifentanil as premedication for tracheal intubation in preterm neonates. The pharmacokinetics of propofol was studied in 25 neonates after a bolus injection of $3000 \mu \mathrm{g} / \mathrm{kg}$ [109] and found that there is a remarkable variation in the propofol $\mathrm{Cl}$ which may be influenced by postmenstrual and postnatal ages.

Malagon et al. [25] compared the effect of three anaesthetics: midazolam, propofol, and sevoflurane, on the postoperative production of cardiac troponin $\mathrm{T}$ in 90 pediatric patients undergoing cardiac surgery. Patients received premedication consisting of oral atropine $(20 \mu \mathrm{g} / \mathrm{kg})$ and midazolam $(500 \mu \mathrm{g} / \mathrm{kg}) 30 \mathrm{~min}$ before induction of anaesthesia. Anaesthesia was induced with sevoflurane $(1 \mu \mathrm{g} / \mathrm{kg})$, followed by a bolus of sufentanil $(1 \mu \mathrm{g} / \mathrm{kg})$ and pancuronium $(200 \mu \mathrm{g} / \mathrm{kg})$. The groups were comparable with respect to sex, age, weight, type of surgery, cardiopulmonary bypass, aortic cross clamp, and circulatory arrest time. The values for acyanotic patients were similar with midazolam, propofol, and sevoflurane. The corresponding values for cyanotic patients were similar to the three anaesthetics. There was a significant correlation between ventilator hours and troponin $\mathrm{T}$ concentrations, at the time of 8 hours, in the sevoflurane group $(r=0.45)$ and midazolam group $(r=0.50)$ but not in the propofol group. The present findings show that the postoperative production of troponin $\mathrm{T}$, in pediatric patients undergoing cardiac surgery, is similar to midazolam, propofol, or sevoflurane anaesthesia.

Hartwig et al. [17] studied the continuous intravenous sedation using midazolam and fentanyl in patients recovered in the pediatric intensive care unit. Twenty-four artificially ventilated children, aged from 26 days to 5 years (17 infants younger than 1 year) received an intravenous midazolam infusion of $100 \mu \mathrm{g} / \mathrm{kg}$ per hour. Fifteen of the 24 children 
received a combination of midazolam with fentanyl; the latter was infused at a rate of 0.5 to $2 \mu \mathrm{g} / \mathrm{kg}$ per hour. The mean duration of fentanyl infusion was 64 hours (range: 20 to 188 hours). No cardiovascular or respiratory adverse effects were seen. After stopping the fentanyl infusion, the children were sedated with midazolam. With midazolam as the only sedative drug, a significantly $(P<0.05)$ higher mean infusion rate of midazolam was necessary to reach a reliable sedation and it was of $209 \mu \mathrm{g} / \mathrm{kg}$ per hour (range: 100 to $500 \mu \mathrm{g} / \mathrm{kg}$ per hour). Mean serum concentration of midazolam decreased from $513 \mu \mathrm{g} / \mathrm{L}$ (range: 124 to $1,093 \mu \mathrm{g} / \mathrm{L}$ ) to $330 \mu \mathrm{g} / \mathrm{L}$ (range: $58 \mu \mathrm{g} / \mathrm{L}$ to $1,240 \mu \mathrm{g} / \mathrm{L}$ ) after 4 to 5 days. Midazolam $\mathrm{Cl}$ increased in relation to the duration of midazolam therapy $(r=0.544$; $P<0.01)$. In the early phase of midazolam therapy, $\mathrm{Cl}$ of midazolam was $5.8+3.8 \mathrm{~mL} / \mathrm{kg}$ per min and increased significantly by $133 \%$ to $13.6+10.6 \mathrm{~mL} / \mathrm{min}$ per min in the late phase of therapy. The reason for the increase of midazolam $\mathrm{Cl}$ may be either an increase of the $\mathrm{Vd}$ or an increase of the hepatic $\mathrm{Cl}$ due to an enzyme induction of midazolam or by increasing hepatic blood flow during a treatment over a longer period. During the first 24 to 72 hours of midazolam therapy, the sedation score was significantly correlated with the serum midazolam concentration $(r=0.76 ; P<0.001)$. The desirable sedation score could be achieved during this time period at a serum concentration between 100 and $500 \mathrm{ng} / \mathrm{mL}$ with an infusion rate of 100 to $400 \mu \mathrm{g} / \mathrm{kg}$ per hour. Midazolam seems to guarantee reliable sedation and anxiolytic action. The evaluation of the sedation score showed that reliable sedation can be achieved at a midazolam infusion of 100 to $400 \mu \mathrm{g} / \mathrm{kg}$ per hour and at a serum midazolam concentration between 100 and $500 \mathrm{ng} / \mathrm{mL}$. In combination with fentanyl, the midazolam infusion rate could be held at a lower level. Continuous intravenous infusion of fentanyl and midazolam has been shown to provide satisfactory analgesia.

Ketamine and midazolam are commonly used in children undergoing cardiac catheterization. Jobeir et al. [110] reviewed pediatric cardiac catetherization procedures in 154 patients (age from 0.3 to 192 months) who underwent a total of 205 procedures. They received ketamine $(n=79 ; 1.05 \pm$ $0.88 \mathrm{mg} / \mathrm{kg}$ per hour), midazolam $(n=35 ; 1.57 \pm 1.03 \mathrm{mg} / \mathrm{kg}$ per hour), or both ( $n=91$; ketamine, $1.13 \pm 0.84 \mathrm{mg} / \mathrm{kg}$ per hour, and midazolam, $1.57 \pm 1.03 \mathrm{mg} / \mathrm{kg}$ per hour). In $18.5 \%$ of patients there were complex cardiac lesions. Preand postprocedure systolic and diastolic mean blood pressure were $72 \pm 14$ and $68 \pm 12 \mathrm{mmHg}$, respectively. Mean procedure time was $79 \pm 36.2 \mathrm{~min}$. The anaesthesiologist's assistance was required by the cardiologist in 21 procedures. Pre- and postprocedure $\mathrm{O}_{2}$ saturation were $93.19 \pm 8.72$ and $93.63 \pm 8.3$, respectively. The mortality was zero. The two groups were not different in relation to the drug use $(P=$ $0.283)$ or the complexity of the cardiac lesion $(P=0.051)$. However, there was significant difference between the two regarding the need for supporting drugs (3/21 versus $3 / 184$; $P=0.02)$ or oxygen treatment $(7 / 21$ versus $26 / 184 ; P=$ 0.014). These authors conclude that low dose of ketamine and midazolam can be administered safely to most pediatric patients by the cardiologist, who can safely predict the need for an anaesthesiologist.
3.14. Adverse Effects of Midazolam in Neonates. Midazolam is incompatible with fat emulsion, albumin, ampicillin, bumetanide, cefepime, ceftazidime, dexamethasone, fosphenytoin, furosemide, hydrocortisone succinate, micafungin, nafcillin, dimenhydrinate, perfenazine, ranitidine hydrochloride, thiopental, prochlorperazine edisylate, and sodium bicarbonate [3, 111]. Ketoconazole and erythromycin are potent inhibitors of CYP3A4 and must not be used in association with midazolam.

There have been reports of life-threatening adverse respiratory and cardiovascular events occurring after administration of midazolam. Pain, tenderness, and thrombophlebitis have occurred following injection of midazolam. Hiccups have been reported. Death due to respiratory depression, hypotension, or cardiac arrest has been reported in patients given intravenous midazolam for conscious sedation [111].

Midazolam is not free from adverse effects when administered to neonates. The first intravenous loading dose of midazolam administered to premature infants not infrequently causes respiratory depression, with hypotension, a fall in cerebral blood flow, and paradoxical agitation [1]. The paradoxical effect such as hyperexcitability and myoclonus may be responsible for the low number of $\mathrm{GABA}_{\mathrm{A}}$ receptors in the neonate [72].

Respiratory depression and hypotension are common when midazolam is used in association with narcotics or following rapid bolus administration. Hypotension has also been reported after continuous infusion of midazolam. The percentage of infants who develop hypotension varies with the studies. Seizure-like myoclonus has been reported in $8 \%$ of premature infants receiving continuous infusion [3]. This also may occur following rapid bolus administration and in patients with underlying disorders of the central nervous system. Nasal administration may be uncomfortable because of a burning sensation [3]. Drug accumulation may occur with repeated doses, prolonged infusion therapy of midazolam, or concurrent administration of cimetidine, erythromycin, or fluconazole [3].

Van den Anker and Sauer [112] observed several adverse effects in premature neonates with a gestational age below 32 weeks. Heart rate and arterial blood pressure decreased directly following an intravenous bolus injection of $200 \mu \mathrm{g} / \mathrm{kg}$ midazolam, but the most disturbing observation was the appearance of involuntary epileptiform movements lasting for 15 to $30 \mathrm{sec}$. The pathogenesis of this phenomenon is speculative, but perhaps in these preterm infants the decrease in arterial pressure and heart rate has also an impact on cerebral blood flow or there is a direct effect of midazolam on the brain.

$\mathrm{Ng}$ et al. [21] recently reviewed the effects of midazolam administered intravenously to infants aged 28 days or less for sedation. These authors reached the conclusion that there are no sufficient data to administrate midazolam intravenously for sedation to neonates undergoing intensive care. Since brain maturation is incomplete in infants, side effects of centrally acting drugs may differ from those in older patients [75].

The major adverse effects associated with continuous infusion of midazolam are related to tolerance and an 
associated abstinence or withdrawal syndrome [71, 76, 113, 114]. Withdrawal syndromes with central nervous system manifestations have been observed. These syndromes have been characterized by seizures, agitation, inability to communicate, and hallucinations or by somatic manifestations such as vomiting, tachycardia, and fever. Bergman et al. [114] suggested that prolonged administration of midazolam to infants, especially to those who had hypoalbuminemia or who were receiving concomitant fentanyl, may produce a long-lasting encephalopathy. Hepatic biotransformation do not mature until 5 months of age; midazolam is metabolized slowly in young infants. Since brain maturation is incomplete in this age group, side effects of centrally acting drugs, including manifestations of an abstinence syndrome, may differ from those in older patients. Midazolam is highly bound to plasma protein (98\% in adults [5]); low serum albumin concentrations may result in higher brain levels and may exacerbate the effects of midazolam by increasing the plasma concentration of unbound drug [115].

Harte et al. [116] evaluated the effects of intravenous midazolam injection on cerebral blood flow in very low birthweight ventilated infants. Ten infants, with birthweight $\leq 1500 \mathrm{~g}$, were treated with an intravenous bolus of $100 \mu \mathrm{g} / \mathrm{kg}$ midazolam. No change in heart rate occurred during the study period, while mean arterial blood pressure decreased by $3 \mathrm{mmHg}, 5 \mathrm{~min}$ after midazolam administration, compared to baseline values. A nonspecific fall in transcutaneous $\mathrm{PCO}_{2}$ was seen at $20 \mathrm{~min}$ after midazolam administration. Mean cerebral blood flow decreased from baseline by $12 \%$ at $5 \mathrm{~min}$ after midazolam administration then returned to predose values. Midazolam concentrations in the therapeutic range were proved to be effective in sedation of pediatric intensive care infants. As only minor cerebral and hemodynamic effects were found with the use of midazolam in stable ventilated preterm infants, it appears that midazolam is a safe, shortterm sedative agent.

The administration of a loading dose of $200 \mu \mathrm{g} / \mathrm{kg}$ midazolam, followed by a constant infusion of $200 \mu \mathrm{g} / \mathrm{kg}$ per hour, to 11 ventilated premature infants, caused changes in cerebral oxygenation and hemodynamics [117]. Van Leuven et al. [118] reported a brief and moderate suppression of the electroencephalogram background pattern, lasting less than 2 hours in 4 out of 15 infants, after a loading dose of $50 \mu \mathrm{g} / \mathrm{kg}$ midazolam, followed by a continuous infusion of $150 \mu \mathrm{g} / \mathrm{kg}$ per hour. Harte et al. [116] reported minor cerebral and hemodynamic effect after the intravenous bolus administration of $100 \mu \mathrm{g} / \mathrm{kg}$ of midazolam to 10 infants with a birthweight $\leq 1500 \mathrm{~g}$.

\section{Discussion}

The present paper reviews the clinical pharmacology of midazolam; most of the work was performed in neonates, and several data have been obtained in children. Benzodiazepines provide effective control of patient agitation without imposing a significant load on the cardiovascular system. Midazolam is a short-acting benzodiazepine with rapid onset of sedation and is preferable to diazepam. $t_{1 / 2}$ of midazolam is 22-fold shorter than that of diazepam [5]. In adults, midazolam $t_{1 / 2}, \mathrm{Cl}$, and Vd are 1.9 hours, $6.6 \mathrm{~mL} / \mathrm{kg}$ per min, and $1.1 \mathrm{~L} / \mathrm{kg}$, respectively. In healthy preterm infants, $t_{1 / 2}$ is 3.3 fold longer, $\mathrm{Cl}$ is 4.4 -fold smaller, and $\mathrm{Vd}$ is $1.1 \mathrm{~L} / \mathrm{kg}$ in adult and neonates. The rate of midazolam elimination is slower in infants than in adults. Midazolam is mainly eliminated by metabolism in adults. It is hydroxylated in position 1 to form 1-hydroxymidazolam by CYP3A4 and CYP3A5. These enzymes surge in the liver during the first weeks of life $[8,9$, 11] and thus their activities and, consequently, the metabolic rate of midazolam are lower in neonates than in older infants and adults. These findings explain the longer $t_{1 / 2}$ and the slower $\mathrm{Cl}$ observed in neonates than in older infants and adults.

Children, with an age greater than 2 years, had a $\mathrm{Cl}$ of midazolam that ranged from 5.8 to $13.6 \mathrm{~mL} / \mathrm{kg}$ per min (mean $\pm \mathrm{SD}=9.6 \pm 3.5 \mathrm{~mL} / \mathrm{kg} / \mathrm{min}$ ) [17, 47]. The work based on 18 patients, aged from 2 days to 17 years, with half of the patients having an age less than 6 months, revealed that $\mathrm{Cl}$ of midazolam was $5.0 \pm 3.9 \mathrm{~mL} / \mathrm{kg}$ per $\mathrm{min}$ [34]. This estimate is lower than that reported in patients with age greater than 2 years [17, 47]. Thus, $\mathrm{Cl}$ of midazolam increases with the age up to at least 2 years of life.

Disease affects the pharmacokinetics of midazolam. A patient suffering from renal failure, with malignant hypertension, and having a creatinine concentration of $691 \mu \mathrm{mol} / \mathrm{L}$ and treated with midazolam, had a $t_{1 / 2}, \mathrm{Vd}$, and $\mathrm{Cl}$ of this drug 6.3-fold longer, 14.5-fold greater, and 2.6-fold larger, respectively, [34] than the normal values [26]. Multiple organ failure reduces the $\mathrm{Cl}$ of midazolam [27]. The severity of disease lowers the $\mathrm{Cl}$ of midazolam, likely by reducing the activities of CYP3A4 and CYP3A5.

Fifteen preterm infants, requiring mechanical ventilation, were treated with midazolam continuous infusion of $60 \mu \mathrm{g} / \mathrm{kg}$ per hour [28]. They had a $t_{1 / 2}$ 1.9-fold longer than the normal value [26]. Some of these infants were treated with different drugs; 7 infants received fentanyl, a substrate of CYP3A4 [52]. Fentanyl may compete with the metabolism of midazolam reducing the midazolam hydroxylation rate, thus lengthening the midazolam $t_{1 / 2}$. The long $t_{1 / 2}$ of midazolam observed by Jacqz-Aigrain et al. [28] may reflect the effect of the mechanical ventilation and the interaction with drugs coadministered with midazolam. ECMO therapy increases several times $t_{1 / 2}, \mathrm{Cl}$, and Vd of midazolam [31, 119].

In literature, there are three studies on the population pharmacokinetics of midazolam [32-34]. Burtin et al. [32] studied 187 neonates, with a gestational age ranging from 26 to 42 weeks, and Lee et al. [33] studied 60 preterm infants, with a gestational age ranging between 24 and 31 weeks. All these infants underwent mechanical ventilation. Mean $t_{1 / 2}$ was 1.6-fold greater [32] than the normal value [26] and 2.2fold greater [33] than normal estimate [26]. These findings suggest that mechanical ventilation may increase midazolam $t_{1 / 2}$ in neonates. The infants studied by Lee et al. [33] had a smaller gestational age than the infants studied by Burtin et al. [32]. The longer $t_{1 / 2}$ observed by Lee et al. [33] might, at least in part, reflect the different gestational ages. The population kinetics of midazolam was studied in 18 pediatric patients, aged from 2 days to 17 years; half of the patients had an age $<6$ 
months [34]. Midazolam $t_{1 / 2}, \mathrm{Cl}$, and Vd were $5.5 \pm 3.5$ hours, $5.0 \pm 3.9 \mathrm{~mL} / \mathrm{kg}$ per $\mathrm{min}$, and $1.7 \pm 1.1 \mathrm{~L} / \mathrm{kg}$, respectively. These parameters were 0.87 -fold lower, 3.0 -fold higher, and 1.5-fold larger than the normal values. These data suggest that the $\mathrm{Cl}$ of midazolam increases with the neonatal development.

The data on midazolam pharmacodynamics in neonates are few and do not allow any conclusion. De Wildt et al. [54] did not find any relationship between sedation level category and drug concentrations. Vet et al. [27] did not find a correlation between inflammation severity and COMFORT score. Trouiller et al. [64] and Arbour et al. [65] stated that the optimal measure, to monitor the pharmacodynamic endpoint, still needs to be determined.

Neonates may undergo uncomfortable procedures and may experience moderate to severe pain in the "neonatal intensive care unit." The availability of an appropriate sedative that reduces the stress and pain is desirable. Midazolam is an effective sedative and represents a convenient choice among the sedatives because of its fast onset of action and the rapid termination of effect. The use of midazolam for newborn sedation remains empirical, and further research on the effectiveness and safety of midazolam in ventilated neonates is needed before its employment can be considered in routine clinical use $[22,111]$.

Sedation of neonates with midazolam may be performed by intravenous administration (bolus or continuous infusion) or by intranasal administration when minimal sedation is required [79]. The median initial dose of intranasal midazolam is $400 \mu \mathrm{g} / \mathrm{kg}$ (range: 300 to $800 \mu \mathrm{g} / \mathrm{kg}$ ). The bioavailability of intranasal midazolam ranged from $50 \%$ to $83 \%$ [83-85]. A second dose of intranasal midazolam, 10 to $15 \mathrm{~min}$ after the first dose, to obtain the desired level of sedation, may be administered. The oral administration of midazolam is not used in neonates and only two reports were found [2, 6]. No information is available in literature on the sublingual administration of midazolam to neonates.

Treluyer et al. [77] determined the minimal effective dose of intravenous midazolam required for appropriate sedation in $95 \%$ of infants, 1 hour after sedation. The sedation procedure was considered a success if all the following criteria were met: no agitation, no grimacing, and no crying facial expression before and during tracheal suctioning. Administering $200 \mu \mathrm{g} / \mathrm{kg}$ midazolam, the final estimated probability of success is $76.9 \%$. Using lower midazolam concentrations, the probability of success decreased.

Mulla et al. [30] administered diazepam to 45 infants to obtain a plasma midazolam concentration between 200 and $1000 \mathrm{ng} / \mathrm{mL}$ within 24 hours to start treatment. Infants, with age greater than 33 weeks of gestation, received a continuous infusion of midazolam of $60 \mu \mathrm{g} / \mathrm{kg}$ per hour. Infants, below 33 weeks of gestation, received the same continuous infusion rate during the first 24 hours of treatment, followed by a continuous infusion of $30 \mu \mathrm{g} / \mathrm{kg}$ per hour of midazolam. Mean midazolam concentrations were $634 \pm 234 \mathrm{ng} / \mathrm{mL}, 628$ $\pm 327 \mathrm{ng} / \mathrm{mL}$, and $543 \pm 327 \mathrm{ng} / \mathrm{mL}$ at 24 and 48 hours and at the end of treatment. Remarkable variability in midazolam plasma concentrations was observed, but none of the infants had levels of midazolam below $200 \mathrm{ng} / \mathrm{mL}$ and only 2 infants had a plasma concentration of midazolam above $1000 \mathrm{ng} / \mathrm{mL}$.
A dose of midazolam between 50 and $400 \mu \mathrm{g} / \mathrm{kg}$ per hour produced midazolam concentrations sufficient for sedation of infants [17]. Dosage of midazolam must be increased during therapy due an increase of midazolam $\mathrm{Cl}$. Arya and Ramji [19] administered midazolam as a bolus of $200 \mu \mathrm{g} / \mathrm{kg}$, followed by a continuous infusion of $60 \mu \mathrm{g} / \mathrm{kg}$ per hour, to 17 infants with a body weight $<2000 \mathrm{~g}$, undergoing mechanical ventilation. No significant adverse effects were observed. The course of mechanical ventilation was not influenced by the use of midazolam. These authors observed that the behavioural assessment was used to demonstrate the sedative effect of midazolam in ventilated infants.

Data describing midazolam pharmacokinetics following oral administration to neonates are few; only two articles are available in literature $[2,6]$. A single oral dose of $100 \mu \mathrm{g} / \mathrm{kg}$ was administered to infants $(n=15)$ with gestational age ranging from 26 to 31 weeks. The apparent oral $\mathrm{Cl}$ and $\mathrm{Vd}$ and the plasma $t_{1 / 2}$ (given as median) were $2.7 \mathrm{~mL} / \mathrm{kg}$ per min, $1.4 \mathrm{~L} / \mathrm{kg}$, and $t_{1 / 2} 7.6$ hours, respectively. These values are not considerably different from the normal values. The absolute bioavailability " $F$ " of midazolam was 0.49 .

The neonatal period is one of the highest risk periods for seizures [92], which occur in $1 \%$ to $5 \%$ of neonates [93]. Little information is available on the treatment of neonatal seizures by midazolam. This drug emerged as an antiepileptic drug in the 1970s, and more recently it has become an effective agent for the treatment of status epilepticus refractory to standard antiepileptic treatment. Rapid control of the status epilepticus has been demonstrated with midazolam. This drug produced a complete clinical and electrographic response in neonates refractory to phenobarbital and phenytoin $[23,24,96]$.

The efficacy of a combination of midazolam and phenytoin, in treating generalized convulsive status epilepticus, was studied in 122 children with the median age of 24.4 months [101]. Forty-three percent of infants required artificial ventilation. Thirty-two percent of the patients developed respiratory insufficiency during initial therapy with midazolam. Eight-nine percent of infants managed on midazolam and phenytoin.

Midazolam successfully managed seizures in 32 neonates who did not respond to diazepam, phenytoin, or phenobarbital [23]. Midazolam was given as an intravenous bolus dose of $100 \mu \mathrm{g} / \mathrm{kg}$ followed by a continuous infusion of 1 to $15 \mu \mathrm{g} / \mathrm{kg}$ per min. Twelve patients (38\%) developed hypotension. Midazolam emerged as a treatment option against the status epilepticus in patients who did not respond to diazepam, phenytoin, or phenobarbital [100]. Compared with phenobarbital, midazolam has fewer hemodynamic consequences, minimizing the need for invasive monitoring [102].

Many drugs depress the function of the central nervous system producing sedation in ventilated infants. They are the opioids (fentanyl, morphine, and diamorphine), the sedativehypnotic midazolam, and the anaesthetic propofol. Mahmoudian and Zadeh [106] did not find statistical differences regarding pain, stress level, and adverse effects between midazolam and propofol.

Hartwig et al. [17] experienced the treatment of midazolam with that of fentanyl in patients recovered in the 
"neonatal intensive care unit". Twenty-four children were artificially ventilated for respiratory support after cardiac surgery. Their age ranged from 26 days to 5 years (17 infants were younger than 1 year) and they received an intravenous bolus of 100 or $200 \mu \mathrm{g} / \mathrm{kg}$ midazolam followed by an infusion of this drug at a rate of $100 \mu \mathrm{g} / \mathrm{kg}$ per hour. Fifteen of the 24 infants received a combination of midazolam with fentanyl. The latter was infused at a rate of 0.5 to $2 \mu \mathrm{g} / \mathrm{kg}$ per hour. No cardiovascular or respiratory adverse effects were seen. Midazolam guarantees reliable sedation and anxiolytic action. With midazolam, as the only sedative drug, a significantly higher mean infusion rate of $209 \mu \mathrm{g} / \mathrm{kg}$ per hour (range: 100 to $500 \mu \mathrm{g} / \mathrm{kg}$ per hour) was necessary to reach a reliable sedation. In the early phase of midazolam therapy, $\mathrm{Cl}$ was $5.8 \pm 3.8 \mathrm{~mL} / \mathrm{kg}$ per min and increased by $133 \%$ to $13.6 \pm 10.6 \mathrm{~mL} / \mathrm{kg}$ per $\mathrm{min}$ in the late phase of therapy.

Ketamine was infused at a rate of $1050 \pm 880 \mu \mathrm{g} / \mathrm{kg}$ per hour $(n=79)$ and midazolam infusion was $140 \pm 90 \mu \mathrm{g} / \mathrm{kg}$ per hour $(n=35)$. There were no differences between the two groups regarding the need for supporting drugs or oxygen treatment. In $18.5 \%$ of patients there were complex cardiac lesions. No difference was found in relation to the drug used $(P=0.283)$ or the complexity of cardiac lesions $(P=$ 0.051). These authors conclude that low dose of ketamine and midazolam can be administered safely to most pediatric patients by the cardiologist, who can safely predict the need for an anaesthesiologist.

Life-threatening adverse respiratory and cardiovascular events have been reported in adults after midazolam administration. Pain, tenderness, and thrombophlebitis have occurred following intravenous midazolam administration [109]. In neonates, intravenous midazolam may cause respiratory depression, with hypotension and a fall in cerebral blood flow. Myoclonus is sometimes seen, and paradoxical agitation has been reported [1]. The paradoxical effect such as hyperexcitability and myoclonus are due to the low number of $\mathrm{GABA}_{\mathrm{A}}$ receptors present in the neonate [72].

The major adverse effects associated with continuous infusion of midazolam are related to tolerance and an associated abstinence or withdrawal syndrome $[21,71,76,112]$. One hundred $\mu \mathrm{g} / \mathrm{kg}$ midazolam reduces the mean arterial blood pressure by $12 \%$ at $5 \mathrm{~min}$ after midazolam [114]. Hypotension may occur after continuous intravenous infusion of midazolam to neonates. The percentage of neonates who developed hypotension varies with the studies. $\mathrm{Hu}$ et al. [23] observed hypotension in $38 \%$ of infants treated with a continuous infusion of midazolam, ranging from 1 to $15 \mu \mathrm{g} / \mathrm{kg}$ per min, to treat seizures. Twenty-seven percent of the infants receiving a continuous midazolam infusion of $60 \mu \mathrm{g} / \mathrm{kg}$ per hour developed hypotension [28]. These infants were treated with several drugs and the contribution of these drugs in developing hypotension is unknown. Hypotension has been reported in few infants, with respiratory distress syndrome, who received a midazolam infusion of $60 \mu \mathrm{g} / \mathrm{kg}$ per hour [78].

In conclusion, midazolam is a safe and effective drug, which may be used as a sedative or as an antiepileptic for the treatment of infants who are refractory to standard antiepileptic therapy. Midazolam is particularly useful in the treatment of the status epilepticus in infants. Midazolam is also used as an anaesthetic, but information about midazolam as an anaesthetic is lacking in neonates. Midazolam is extensively hydroxylated by two cytochrome P-450 forms, namely, CYP3A4 and CYP3A5. These enzymes surge in the liver during the first weeks of life. Neonates have a lower expression of these enzymes than older infants and adults. Consequently, the metabolic rate of midazolam is lower in neonates. Diseases affect the pharmacokinetics of midazolam; they may reduce the $\mathrm{Cl}$ or prolong $t_{1 / 2}$ of midazolam. It is likely that these effects are due to the lowering of CYP3A4 and CYP3A5 activities. We feel that further research is required to ensure that the doses of midazolam recommended for the treatment of neonates are evidence-based.

\section{Conflict of Interests}

The author declares that there is no conflict of interests regarding the publication of this paper.

\section{Acknowledgments}

This work has been supported by the Ministry of the University and Scientific and Technologic Research (Rome, Italy). The author thanks Dr. Rosa Baviello and Dr. Ida Bertolini, of the Medical Library of the University of Pisa, for the prompt retrieving of the literature. Particular thanks are due to Dr. Tessa Piazzini, of the Biomedical Library of the University of Florence, who performed the bibliographic search with EMBASE.

\section{References}

[1] Neonatal Formulary, John Wiley \& Sons, West Sussex, UK, 6th edition, 2011.

[2] S. N. De Wildt, G. L. Kearns, S. D. Sie, W. C. J. Hop, and J. N. Van Den Anker, "Pharmacodynamics of intravenous and oral midazolam in preterm infants," Clinical Drug Investigation, vol. 23, no. 1, pp. 27-38, 2003.

[3] T. E. Young and M. B. Neofax, A Manual of Drugs Used in Neonatal Care, Thomson Reuters, Montvale, NJ, USA, 23rd edition, 2010.

[4] S. J. Mihi and R. A. Harris, "Hypnotic and sedatives", in Goodman and Gilman's. The Pharmacological Basis of Therapeutics, L. Brunton, B. Chabner, and B. Knollman, Eds., McGraw Hill, New York, NY, USA, 12th edition, 2011.

[5] K. E. Thummel and D. D. Shen, "Isoherranen N. Design and optimization of dosage regimens: pharmacokinetic data," in Goodman and Gilman's. The Pharmacological Basis of Therapeutics, L. Brunton, B. Chabner, and B. Knollman, Eds., McGraw Hill, New York, NY, USA, 12th edition, 2011.

[6] S. N. De Wildt, G. L. Kearns, W. C. J. Hop, D. J. Murry, S. M. Abdel-Rahman, and J. N. Van Den Anker, "Pharmacokinetics and metabolism of oral midazolam in preterm infants," British Journal of Clinical Pharmacology, vol. 53, no. 4, pp. 390-392, 2002.

[7] H. Oldenhof, M. De Jong, A. Steenhoek, and R. Janknegt, "Clinical pharmacokinetics of midazolam in intensive care patients, a wide interpatient variability?" Clinical Pharmacology and Therapeutics, vol. 43, no. 3, pp. 263-269, 1988. 
[8] G. L. Kearns, S. M. Abdel-Rahman, S. W. Alander, D. L. Blowey, J. S. Leeder, and R. E. Kauffman, "Developmental pharmacology - drug disposition, action, and therapy in infants and children," The New England Journal of Medicine, vol. 349, no. 12, pp. 1157-1167, 2003.

[9] D. Lacroix, M. Sonnier, A. Moncion, G. Cheron, and T. Cresteil, "Expression of CYP3A in the human liver-evidence that the shift between CYP3A7 and CYP3A4 occurs immediately after birth," European Journal of Biochemistry, vol. 247, no. 2, pp. 625634, 1997.

[10] S. N. De Wildt, G. L. Kearns, D. J. Murry, G. Koren, and J. N. Van Den Anker, "Ontogeny of midazolam glucuronidation in preterm infants," European Journal of Clinical Pharmacology, vol. 66, no. 2, pp. 165-170, 2010.

[11] S. A. Wrighton, W. R. Brian, M.-A. Sari et al., "Studies on the expression and metabolic capabilities of human liver cytochrome P450IIIA5 (HLp3)," Molecular Pharmacology, vol. 38, no. 2, pp. 207-213, 1990.

[12] R. D. Mellon, A. F. Simone, and B. A. Rappaport, "Use of anesthetic agents in neonates and young children," Anesthesia and Analgesia, vol. 104, no. 3, pp. 509-520, 2007.

[13] V. Jevtovic-Todorovic, R. E. Hartman, Y. Izumi et al., "Early exposure to common anesthetic agents causes widespread neurodegeneration in the developing rat brain and persistent learning deficits," Journal of Neuroscience, vol. 23, no. 3, pp. 876882, 2003.

[14] C. Young, V. Jevtovic-Todorovic, Y.-Q. Qin et al., "Potential of ketamine and midazolam, individually or in combination, to induce apoptotic neurodegeneration in the infant mouse brain," British Journal of Pharmacology, vol. 146, no. 2, pp. 189-197, 2005.

[15] E. Ng, A. Taddio, and A. Ohlsson, "Intravenous midazolam infusion for sedation of infants in the neonatal intensive care unit," Cochrane Database of Systematic Reviews, no. 2, article CD002052, 2000.

[16] E. Jacqz-Aigrain, P. Daoud, P. Burtin, L. Desplanques, and F. Beaufils, "Placebo-controlled trial of midazolam sedation in mechanically ventilated newborn babies," The Lancet, vol. 344, no. 8923, pp. 646-650, 1994.

[17] S. Hartwig, B. Roth, and M. Theisohn, "Clinical experience with continuous intravenous sedation using midazolam and fentanyl in the paediatric intensive care unit," European Journal of Pediatrics, vol. 150, no. 11, pp. 784-788, 1991.

[18] K. J. S. Anand, N. McIntosh, H. Lagercrantz, E. Pelausa, T. E. Young, and R. Vasa, "Analgesia and sedation in preterm neonates who require ventilatory support: results from the NOPAIN trial," Archives of Pediatrics and Adolescent Medicine, vol. 153, no. 4, pp. 331-338, 1999.

[19] V. Arya and S. Ramji, "Midazolam sedation in mechanically ventilated newborns: a double blind randomized placebo controlled trial," Indian Pediatrics, vol. 38, no. 9, pp. 967-972, 2001.

[20] L. Lowrie, A. H. Weiss, and C. Lacombe, "The pediatric sedation unit: a mechanism for pediatric sedation," Pediatrics, vol. 102, no. 3, p. E30, 1998.

[21] E. Ng, A. Taddio, and A. Ohlsson, "Intravenous midazolam infusion for sedation of infants in the neonatal intensive care unit," Cochrane Database of Systematic Reviews, no. 1, article CD002052, 2003.

[22] J. V. Aranda, W. Carlo, P. Hummel, R. Thomas, V. T. Lehr, and K. J. S. Anand, "Analgesia and sedation during mechanical ventilation in neonates," Clinical Therapeutics, vol. 27, no. 6, pp. 877-899, 2005.
[23] K.-C. Hu, N.-C. Chiu, C.-S. Ho, S.-T. Lee, and E.-Y. Shen, “Continuous midazolam infusion in the treatment of uncontrollable neonatal seizures," Acta Paediatrica Taiwanica, vol. 44, no. 5, pp. 279-281, 2003.

[24] J. R. Castro Conde, A. A. Hernández Borges, E. Doménech Martínez, C. González Campo, and R. Perera Soler, "Midazolam in neonatal seizures with no response to phenobarbital," Neurology, vol. 64, no. 5, pp. 876-879, 2005.

[25] I. Malagon, K. Hogenbirk, J. van Pelt, M. G. Hazekamp, and J. G. Bovill, "Effect of three different anaesthetic agents on the postoperative production of cardiac troponin $\mathrm{T}$ in paediatric cardiac surgery," British Journal of Anaesthesia, vol. 94, no. 6, pp. 805-809, 2005.

[26] S. N. De Wildt, G. L. Kearns, W. C. J. Hop, D. J. Murry, S. M. Abdel-Rahman, and J. N. Van Den Anker, "Pharmacokinetics and metabolism of intravenous midazolam in preterm infants," Clinical Pharmacology and Therapeutics, vol. 70, no. 6, pp. 525531, 2001.

[27] N. J. Vet, C. W. M. Verlaat, S. N. De Wildt, D. Tibboel, and M. De Hoog, "Daily interruption of sedation in critically ill children," Pediatric Critical Care Medicine, vol. 13, no. 1, article 122, 2012.

[28] E. Jacqz-Aigrain, P. Daoud, P. Burtin, S. Maherzi, and F. Beaufils, "Pharmacokinetics of midazolam during continuous infusion in critically ill neonates," European Journal of Clinical Pharmacology, vol. 42, no. 3, pp. 329-332, 1992.

[29] E. Jacqz-Aigrain, C. Wood, and I. Robieux, "Pharmacokinetics of midazolam in critically ill neonates," European Journal of Clinical Pharmacology, vol. 39, no. 2, pp. 191-192, 1990.

[30] H. Mulla, P. McCormack, G. Lawson, R. K. Firmin, and D. R. Upton, "Pharmacokinetics of midazolam in neonates undergoing extracorporeal membrane oxygenation," Anesthesiology, vol. 99, no. 2, pp. 275-282, 2003.

[31] M. J. Ahsman, M. Hanekamp, E. D. Wildschut, D. Tibboel, and R. A. A. Mathot, "Population pharmacokinetics of midazolam and its metabolites during venoarterial extracorporeal membrane oxygenation in neonates," Clinical Pharmacokinetics, vol. 49, no. 6, pp. 407-419, 2010.

[32] P. Burtin, E. Jacqz-Aigrain, P. Girard et al., "Population pharmacokinetics of midazolam in neonates," Clinical Pharmacology and Therapeutics, vol. 56, no. 6, part 1, pp. 615-625, 1994.

[33] T. C. Lee, B. G. Charles, G. J. Harte, P. H. Gray, P. A. Steer, and V. J. Flenady, "Population pharmacokinetic modeling in very premature infants receiving midazolam during mechanical ventilation: midazolam neonatal pharmacokinetics," Anesthesiology, vol. 90, no. 2, pp. 451-457, 1999.

[34] S. N. De Wildt, M. De Hoog, A. A. Vinks, E. Van Der Giesen, and J. N. Van Den Anker, "Population pharmacokinetics and metabolism of midazolam in pediatric intensive care patients," Critical Care Medicine, vol. 31, no. 7, pp. 1952-1958, 2003.

[35] K. Allegaert, J. N. van den Anker, G. Naulaers, and J. de Hoon, "Determinants of drug metabolism in early neonatal life," Current Clinical Pharmacology, vol. 2, no. 1, pp. 23-29, 2007.

[36] J. A. Ring, H. Ghabrial, M. S. Ching, R. A. Smallwood, and D. J. Morgan, "Fetal hepatic drug elimination," Pharmacology and Therapeutics, vol. 84, no. 3, pp. 429-445, 1999.

[37] M. G. Ladona, B. Lindstrom, C. Thyr, P. Dun-Ren, and A. Rane, "Differential foetal development of the O- and N-demethylation of codeine and dextromethorphan in man," British Journal of Clinical Pharmacology, vol. 32, no. 3, pp. 295-302, 1991.

[38] F. J. Gonzalez, M. Coughtrie, and R. H. Tukey, "Drug Metabolism," in Goodman and Gilman's. The Pharmacological Basis of 
Therapeutics, L. Brunton, B. Chabner, and B. Knollman, Eds., McGraw Hill, New York, NY, USA, 12th edition, 2011.

[39] T. C. Lee and B. Charles, "Measurement by HPLC of midazolam and its major metabolite, 1-hydroxymidazolam in plasma of very premature neonates," Biomedical Chromatography, vol. 10, no. 2, pp. 65-68, 1996.

[40] J. C. Gorski, S. D. Hall, D. R. Jones, M. Van Den Branden, and S. A. Wrighton, "Regioselective biotransformation of midazolam by members of the human cytochrome P450 3A (CYP3A) subfamily," Biochemical Pharmacology, vol. 47, no. 9, pp. 16431653, 1994.

[41] R. W. Wang, D. J. Newton, N. Y. Liu, M. Shou, T. Rushmore, and A. Y. H. Lu, "Inhibitory anti-CYP3A4 peptide antibody: mapping of inhibitory epitope and specificity toward other CYP3A isoforms," Drug Metabolism and Disposition, vol. 27, no. 2, pp. 167-172, 1999.

[42] A. Keubler, J. Weiss, W. E. Haefeli, G. Mikus, and J. Burhenne, "Drug interaction of efavirenz and midazolam: efavirenz activates the CYP3A-mediated midazolam 1'-hydroxylation in vitro," Drug Metab Dispos, vol. 40, no. 6, pp. 1178-1182, 2012.

[43] I. Ince, S. N. de Wildt, M. Y. Peeters et al., "mCritical illness is a major determinant of midazolam clearance in children aged 1 month to 17 years," Therapeutic Drug Monitoring, vol. 34, no. 4, pp. 381-389, 2012.

[44] P. B. Watkins, "Noninvasive tests of CYP3A enzymes," Pharmacogenetics, vol. 4, no. 4, pp. 171-184, 1994.

[45] D. S. Streetman, J. F. Bleakley, J. S. Kim et al., "Combined phenotypic assessment of CYP1A2, CYP2C19, CYP2D6, CYP3A, $\mathrm{N}$-acetyltransferase-2, and xanthine oxidase with the 'Cooperstown cocktail', Clinical Pharmacology and Therapeutics, vol. 68, no. 4, pp. 375-383, 2000.

[46] I. Ince, S. N. de Wildt, C. Wang et al., "A novel maturation function for clearance of the cytochrome P450 3A substrate midazolam from preterm neonates to adults," Clinical Pharmacokinetics, vol. 52, no. 7, pp. 555-565, 2013.

[47] J. G. Reves, R. J. Fragen, H. R. Vinik, and D. J. Greenblatt, "Midazolam: pharmacology and uses," Anesthesiology, vol. 62, no. 3, pp. 310-324, 1985.

[48] T. N. Johnson, M. S. Tanner, C. J. Taylor, and G. T. Tucker, "Enterocytic CYP3A4 in a paediatric population: developmental changes and the effect of coeliac disease and cystic fibrosis," British Journal of Clinical Pharmacology, vol. 51, no. 5, pp. 451460, 2001.

[49] S. N. De Wildt, G. L. Kearns, J. S. Leeder, and J. N. Van Den Anker, "Cytochrome P450 3A. Ontogeny and drug disposition," Clinical Pharmacokinetics, vol. 37, no. 6, pp. 485-505, 1999.

[50] B. J. Anderson and P. Larsson, "A maturation model for midazolam clearance," Paediatric Anaesthesia, vol. 21, no. 3, pp. 302-308, 2011.

[51] K. S. Pang and M. Rowland, "Hepatic clearance of drugs. I. Theoretical considerations of a "well-stirred" model and a "parallel tube" model. Influence of hepatic blood flow, plasma and blood cell binding, and the hepatocellular enzymatic activity on hepatic drug clearance," Journal of Pharmacokinetics and Biopharmaceutics, vol. 5, no. 6, pp. 625-653, 1977.

[52] R. B. Labroo, M. F. Paine, K. E. Thummel, and E. D. Kharasch, "Fentanyl metabolism by human hepatic and intestinal cytochrome P450 3A4: implications for interindividual variability in disposition, efficacy, and drug interactions," Drug Metabolism and Disposition, vol. 25, no. 9, pp. 1072-1080, 1997.

[53] M. Y. M. Peeters, S. A. Prins, C. A. J. Knibbe et al., "Pharmacokinetics and pharmacodynamics of midazolam and metabolites in nonventilated infants after craniofacial surgery," Anesthesiology, vol. 105, no. 6, pp. 1135-1146, 2006.

[54] S. N. De Wildt, M. De Hoog, A. A. Vinks, K. F. M. Joosten, M. Van Dijk, and J. N. Van Den Anker, "Pharmacodynamics of midazolam in pediatric intensive care patients," Therapeutic Drug Monitoring, vol. 27, no. 1, pp. 98-102, 2005.

[55] M. L. Buck, "Pharmacokinetic changes during extracorporeal membrane oxygenation: implications for drug therapy of neonates," Clinical Pharmacokinetics, vol. 42, no. 5, pp. 403-417, 2003.

[56] K. Shekar, J. F. Fraser, M. T. Smith, and J. A. Roberts, "Pharmacokinetic changes in patients receiving extracorporeal membrane oxygenation," Journal of Critical Care, vol. 27, no. 6, pp. 741.e9-741.e18, 2012.

[57] J. W. Mandema, B. Tuk, A. L. Van Steveninck, D. D. Breimer, A. F. Cohen, and M. Danhof, "Pharmcokinetic-pharmacodynamic modeling of the central nervous system effects of midazolam and its main metabolite $\alpha$-hydroxymidazolam in healthy volunteers," Clinical Pharmacology and Therapeutics, vol. 51, no. 6, pp. 715-728, 1992.

[58] A. R. Lloyd-Thomas and P. D. Booker, "Infusion of midazolam in paediatric patients after cardiac surgery," British Journal of Anaesthesia, vol. 58, no. 10, pp. 1109-1115, 1986.

[59] B. B. DeBerry, J. E. Lynch, J. M. Chernin, J. B. Zwischenberger, and D. H. Chung, "A survey for pain and sedation medications in pediatric patients during extracorporeal membrane oxygenation," Perfusion, vol. 20, no. 3, pp. 139-143, 2005.

[60] A. M. Harrison, S. Davis, S. Eggleston, R. Cunningham, R. B. B. Mee, and P. M. Bokesch, "Serum creatinine and estimated creatinine clearance do not predict perioperatively measured creatinine clearance in neonates undergoing congenital heart surgery," Pediatric Critical Care Medicine, vol. 4, no. 1, pp. 5559, 2003.

[61] J. Hughes, A. M. Gill, H. Mulhearn, E. Powell, and I. Choonara, "Steady-state plasma concentrations of midazolam in critically ill infants and children," Annals of Pharmacotherapy, vol. 30, no. 1, pp. 27-30, 1996.

[62] H. M. L. Mathews, I. W. Carson, S. M. Lyons et al., "A pharmacokinetic study of midazolam in paediatric patients undergoing cardiac surgery," British Journal of Anaesthesia, vol. 61, no. 3, pp. 302-307, 1988.

[63] E. L. Swart, P. R. Slort, and F. B. Plötz, "Growing up with midazolam in the neonatal and pediatric intensive care," Current Drug Metabolism, vol. 13, no. 6, pp. 760-766, 2012.

[64] P. Trouiller, P. Fangio, C. Paugam-Burtz et al., "Frequency and clinical impact of preserved bispectral index activity during deep sedation in mechanically ventilated ICU patients," Intensive Care Medicine, vol. 35, no. 12, pp. 2096-2104, 2009.

[65] R. Arbour, J. Waterhouse, M. A. Seckel, and L. Bucher, "Correlation between the Sedation-Agitation Scale and the Bispectral Index in ventilated patients in the intensive care unit," Heart and Lung, vol. 38, no. 4, pp. 336-345, 2009.

[66] S. Björkman, "Prediction of drug disposition in infants and children by means of physiologically based pharmacokinetic (PBPK) modelling: theophylline and midazolam as model drugs," British Journal of Clinical Pharmacology, vol. 59, no. 6, pp. 691-704, 2005.

[67] S. Björkman, "Prediction of cytochrome P450-mediated hepatic drug clearance in neonates, infants and children: how accurate are available scaling methods?" Clinical Pharmacokinetics, vol. 45, no. 1, pp. 1-11, 2006. 
[68] T. N. Johnson, A. Rostami-Hodjegan, and G. T. Tucker, "Prediction of the clearance of eleven drugs and associated variability in neonates, infants and children," Clinical Pharmacokinetics, vol. 45, no. 9, pp. 931-956, 2006.

[69] C. M. Marx, P. G. Smith, L. H. Lowrie et al., "Optimal sedation of mechanically ventilated pediatric critical care patients," Critical Care Medicine, vol. 22, no. 1, pp. 163-170, 1994.

[70] D. L. Silvasi, D. A. Rosen, and K. R. Rosen, "Continuous intravenous midazolam infusion for sedation in the Pediatric Intensive Care Unit," Anesthesia and Analgesia, vol. 67, no. 3, pp. 286-288, 1988.

[71] D. A. Rosen and K. R. Rosen, "Midazolam for sedation in the paediatric intensive care unit," Intensive Care Medicine, vol. 17, supplement 1, pp. S15-S19, 1991.

[72] G. Ancora, E. Garetti, A. Pirelli et al., "Analgesic and sedative drugs in newborns requiring respiratory support," Journal of Maternal-Fetal and Neonatal Medicine, vol. 25, supplement 4, pp. 88-90, 2012.

[73] D. A. Rosen and K. R. Rosen, "Intravenous conscious sedation with midazolam in paediatric patients," International Journal of Clinical Practice, vol. 52, no. 1, pp. 46-50, 1998.

[74] American Academy of Pediatrics, Committee on Drugs, "Guidelines for monitoring and management of pediatric patients during and after sedation for diagnostic and therapeutic procedures," Pediatrics, vol. 89, pp. 1110-1115, 1992.

[75] D. A. Notterman, "Sedation with intravenous midazolam in the pediatric intensive care unit," Clinical Pediatrics, vol. 36 , no. 8 , pp. 449-454, 1997.

[76] J. Hughes, A. Gill, H. J. Leach et al., "A prospective study of the adverse effects of midazolam on withdrawal in critically ill children," Acta Paediatrica, International Journal of Paediatrics, vol. 83, no. 11, pp. 1194-1199, 1994.

[77] J.-M. Treluyer, S. Zohar, E. Rey et al., "Minimum effective dose of midazolam for sedation of mechanically ventilated neonates," Journal of Clinical Pharmacy and Therapeutics, vol. 30, no. 5, pp. 479-485, 2005.

[78] P. Burtin, P. Daoud, E. Jacqz-Aigrain, P. Mussat, and G. Moriette, "Hypotension with midazolam and fentanyl in the newborn," The Lancet, vol. 337, no. 8756, pp. 1545-1546, 1991.

[79] J. P. Lazol and C. G. DeGroff, "Minimal sedation second dose strategy with intranasal midazolam in an outpatient pediatric echocardiographic setting," Journal of the American Society of Echocardiography, vol. 22, no. 4, pp. 383-387, 2009.

[80] N. C. T. Wilton, J. Leight, D. R. Rosen, and U. A. Pandit, "Preanesthetic sedation of preschool children using intranasal midazolam," Anesthesiology, vol. 69, no. 6, pp. 972-975, 1988.

[81] P. Löwhagen, B. B. Johansson, and C. Nordborg, "The nasal route of cerebrospinal fluid drainage in man: a light-microscope study," Neuropathology and Applied Neurobiology, vol. 20, no. 6, pp. 543-550, 1994.

[82] J. Berlin C.M., D. G. May-McCarver, D. A. Notterman et al., "Alternative routes of drug administration-advantages and disadvantages," Pediatrics, vol. 100, no. 1, pp. 143-152, 1997.

[83] P. D. Knoester, D. M. Jonker, R. T. M. Van Der Hoeven et al., "Pharmacokinetics and pharmacodynamics of midazolam administered as a concentrated intranasal spray. A study in healthy volunteers," British Journal of Clinical Pharmacology, vol. 53, no. 5, pp. 501-507, 2002.

[84] A. H. Burstein, R. Modica, M. Hatton, A. Forrest, and F. M. Gengo, "Pharmacokinetics and pharmacodynamics of midazolam after intranasal administration," Journal of Clinical Pharmacology, vol. 37, no. 8, pp. 711-718, 1997.
[85] E. Rey, L. Delaunay, G. Pons et al., "Pharmacokinetics of midazolam in children: comparative study of intranasal and intravenous administration," European Journal of Clinical Pharmacology, vol. 41, no. 4, pp. 355-357, 1991.

[86] G. Ljungman, A. Kreuger, S. Andréasson, T. Gordh, and S. Sörensen, "Midazolam nasal spray reduces procedural anxiety in children," Pediatrics, vol. 105, no. 1, part 1, pp. 73-78, 2000.

[87] N. Griffith, S. Howell, and D. G. Mason, "Intranasal midazolam for premedication of children undergoing day-case anaesthesia: comparison of two delivery systems with assessment of intraobserver variability," British Journal of Anaesthesia, vol. 81, no. 6, pp. 865-869, 1998.

[88] A. Kogan, J. Katz, R. Efrat, and L. A. Eidelman, "Premedication with midazolam in young children: a comparison of four routes of administration," Paediatric Anaesthesia, vol. 12, no. 8, pp. 685-689, 2002.

[89] R. D. Lane and J. E. Schunk, "Atomized intranasal midazolam use for minor procedures in the pediatric emergency department," Pediatric Emergency Care, vol. 24, no. 5, pp. 300-303, 2008.

[90] H. T. Harcke, L. E. Grissom, and M. A. Meister, "Sedation in pediatric imaging using intranasal midazolam," Pediatric Radiology, vol. 25, no. 5, pp. 341-343, 1995.

[91] L. A. Slaughter, A. D. Patel, and J. L. Slaughter, "Pharmacological treatment of neonatal seizures: a systematic review," Journal of Child Neurology, vol. 28, no. 3, pp. 351-364, 2013.

[92] D. Sirsi, S. Nangia, J. LaMothe, B. E. Kosofsky, and G. E. Solomon, "Successful management of refractory neonatal seizures with midazolam," Journal of Child Neurology, vol. 23, no. 6, pp. 706-709, 2008.

[93] M. Eriksson and R. Zetterstrom, "Neonatal convulsions. Incidence and causes in the Stockholm area," Acta Paediatrica Scandinavica, vol. 68, no. 6, pp. 807-811, 1979.

[94] M. J. Painter, M. S. Scher, A. D. Stein et al., "Phenobarbital compared with phenytoin for the treatment of neonatal seizures," The New England Journal of Medicine, vol. 341, no. 7, pp. 485489, 1999.

[95] G. B. Boylan, J. M. Rennie, R. M. Pressler, G. Wilson, M. Morton, and C. D. Binnie, "Phenobarbitone, neonatal seizures, and video-EEG," Archives of Disease in Childhood, vol. 86, no. 3, pp. F165-F170, 2002.

[96] R. D. Sheth, D. J. Buckley, A. R. Gutierrez, M. Gingold, J. B. Bodensteiner, and S. Penney, "Midazolam in the treatment of refractory neonatal seizures," Clinical Neuropharmacology, vol. 19, no. 2, pp. 165-170, 1996.

[97] L. G. van Rooij, L. Hellström-Westas, and L. S. de Vries, "Treatment of neonatal seizures," Seminars in Fetal \& Neonatal Medicine, vol. 18, no. 4, pp. 209-215, 2013.

[98] E. Shany, O. Benzaqen, and N. Watemberg, "Comparison of continuous drip of midazolam or lidocaine in the treatment of intractable neonatal seizures," Journal of Child Neurology, vol. 22, no. 3, pp. 255-259, 2007.

[99] H. Yamamoto, M. Aihara, S. Niijima, and H. Yamanouchi, "Treatments with midazolam and lidocaine for status epilepticus in neonates," Brain and Development, vol. 29, no. 9, pp. 559564, 2007.

[100] G. L. Holmes and J. J. Riviello Jr., "Midazolam and pentobarbital for refractory status epilepticus," Pediatric Neurology, vol. 20, no. 4, pp. 259-264, 1999.

[101] J. C. D. Brevoord, K. F. M. Joosten, W. F. M. Arts, R. W. van Rooij, and M. de Hoog, "Status epilepticus: clinical analysis 
of a treatment protocol based on midazolam and phenytoin," Journal of Child Neurology, vol. 20, no. 6, pp. 476-481, 2005.

[102] A. Kumar and T. P. Bleck, "Intravenous midazolam for the treatment of refractory status epilepticus," Critical Care Medicine, vol. 20, no. 4, pp. 483-488, 1992.

[103] E. Lahat, M. Goldman, J. Barr, T. Bistritzer, and M. Berkovitch, "Comparison of intranasal midazolam with intravenous diazepam for treating febrile seizures in children: prospective randomised study," British Medical Journal, vol. 321, no. 7253, pp. 83-86, 2000.

[104] G. Geldner, M. Hubmann, R. Knoll, and K. Jacobi, "Comparison between three transmucosal routes of administration of midazolam in children," Paediatric Anaesthesia, vol. 7, no. 2, pp. 103109, 1997.

[105] J. McIntyre, S. Robertson, E. Norris et al., "Safety and efficacy of buccal midazolam versus rectal diazepam for emergency treatment of seizures in children: a randomised controlled trial," The Lancet, vol. 366, no. 9481, pp. 205-210, 2005.

[106] T. Mahmoudian and M. M. Zadeh, "Comparison of intranasal midazolam with intravenous diazepam for treating acute seizures in children," Epilepsy and Behavior, vol. 5, no. 2, pp. 253-255, 2004.

[107] R. Carbajal, B. Eble, and K. J. S. Anand, "Premedication for tracheal intubation in neonates: confusion or controversy?" Seminars in Perinatology, vol. 31, no. 5, pp. 309-317, 2007.

[108] M. G. Penido, D. F. De Oliveira Silva, E. C. Tavares, and Y. P. E Silva, "Propofol versus midazolam for intubating preterm neonates: a randomized controlled trial," Journal of Perinatology, vol. 31, no. 5, pp. 356-360, 2011.

[109] K. Allegaert, M. Y. Peeters, R. Verbesselt et al., "Inter-individual variability in propofol pharmacokinetics in preterm and term neonates," British Journal of Anaesthesia, vol. 99, no. 6, pp. 864870, 2007.

[110] A. Jobeir, M. O. Galal, Z. R. Bulbul, L. Solymar, A. Darwish, and A. A. Schmaltz, "Use of low-dose ketamine and/or midazolam for pediatric cardiac catheterization: is an anesthesiologist needed?" Pediatric Cardiology, vol. 24, no. 3, pp. 236-243, 2003.

[111] S. Sweetman, Ed., Martindale: The Complete Drug Reference, Pharmaceutical Press, London, UK, 34th edition, 2005.

[112] J. N. Van den Anker and P. J. J. Sauer, "The use of midazolam in the preterm neonate," European Journal of Pediatrics, vol. 151, no. 2, p. 152, 1992.

[113] R. L. Sheridan, M. McEttrick, G. Bacha, F. Stoddard, and R. G. Tompkins, "Midazolam infusion in pediatric patients with burns who are undergoing mechanical ventilation," Journal of Burn Care and Rehabilitation, vol. 15, no. 6, pp. 515-518, 1994.

[114] I. Bergman, M. Steeves, G. Burckart, and A. Thompson, "Reversible neurologic abnormalities associated with prolonged intravenous midazolam and fentanyl administration," Journal of Pediatrics, vol. 119, no. 4, pp. 644-649, 1991.

[115] T. B. Vree, M. Shimoda, J. J. Driessen et al., "Decreased plasma albumin concentration results in increased volume of distribution and decreased elimination of midazolam in intensive care patients," Clinical Pharmacology and Therapeutics, vol. 46, no. 5, pp. 537-544, 1989.

[116] G. J. Harte, P. H. Gray, T. C. Lee, P. A. Steer, and B. G. Charles, "Haemodynamic responses and population pharmacokinetics of midazolam following administration to ventilated, preterm neonates," Journal of Paediatrics and Child Health, vol. 33, no. 4, pp. 335-338, 1997.
[117] A. A. E. M. Van Alfen-Van Der Velden, J. C. W. Hopman, J. H. G. M. Klaessens, T. Feuth, R. C. A. Sengers, and K. D. Liem, "Effects of midazolam and morphine on cerebral oxygenation and hemodynamics in ventilated premature infants," Biology of the Neonate, vol. 90, no. 3, pp. 197-202, 2006.

[118] K. Van Leuven, F. Groenendaal, M. C. Toet et al., "Midazolam and amplitude-integrated EEG in asphyxiated full-term neonates," Acta Paediatrica, International Journal of Paediatrics, vol. 93, no. 9, pp. 1221-1227, 2004.

[119] H. Mulla, G. Lawson, G. J. Peek, R. K. Firmin, and D. R. Upton, "Plasma concentrations of midazolam in neonates receiving extracorporeal membrane oxygenation," ASAIO Journal, vol. 49, no. 1, pp. 41-47, 2003. 


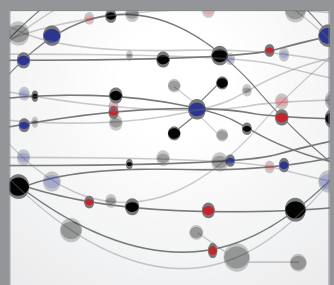

The Scientific World Journal
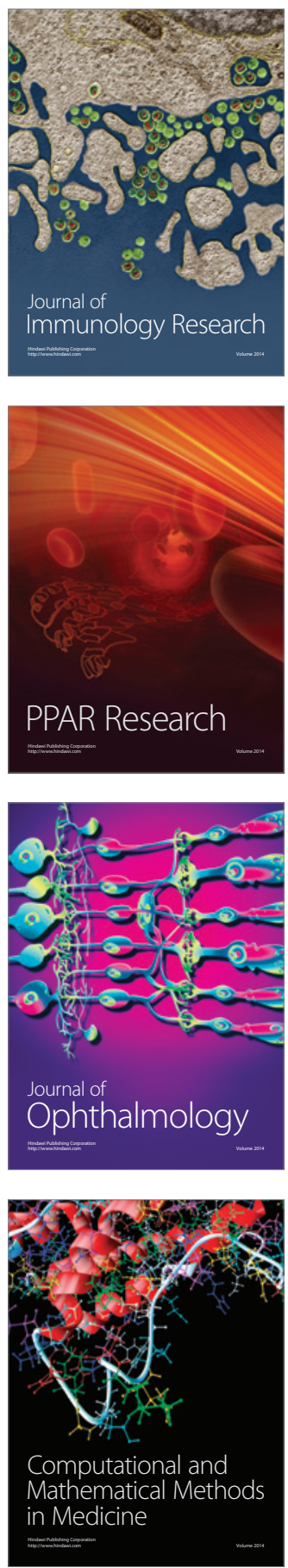

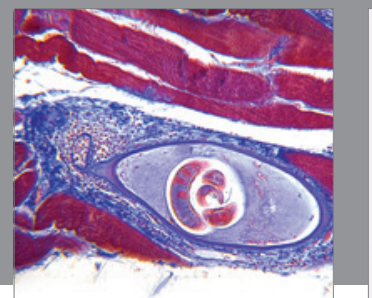

Gastroenterology

Research and Practice
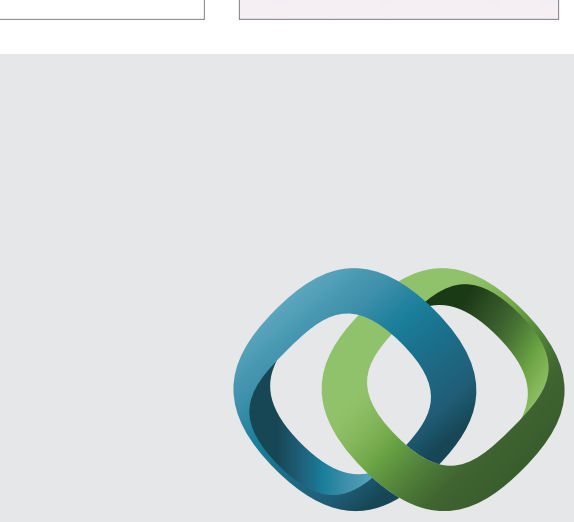

\section{Hindawi}

Submit your manuscripts at

http://www.hindawi.com
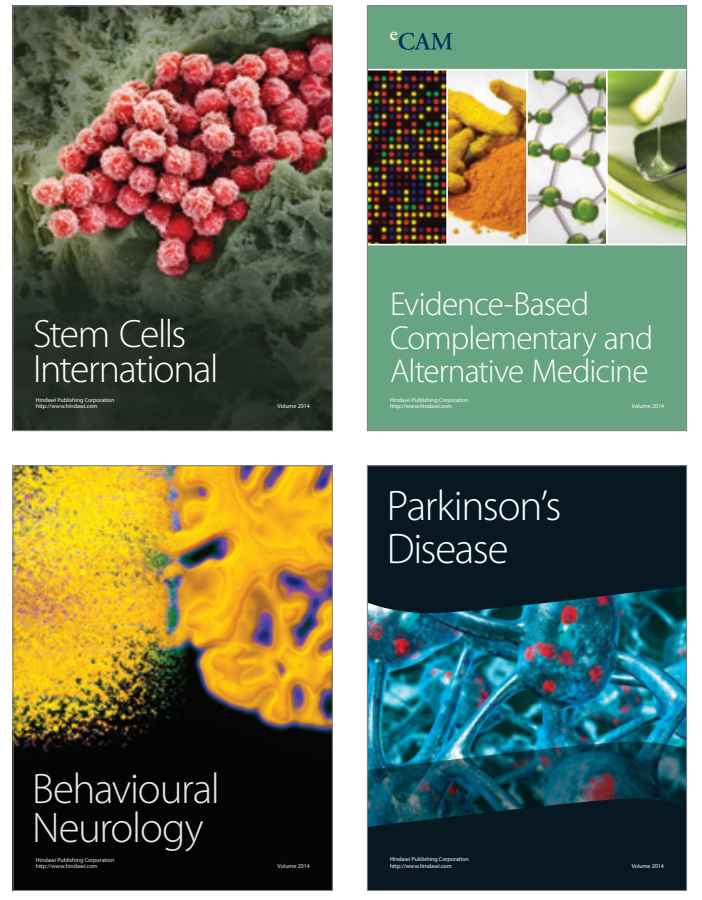
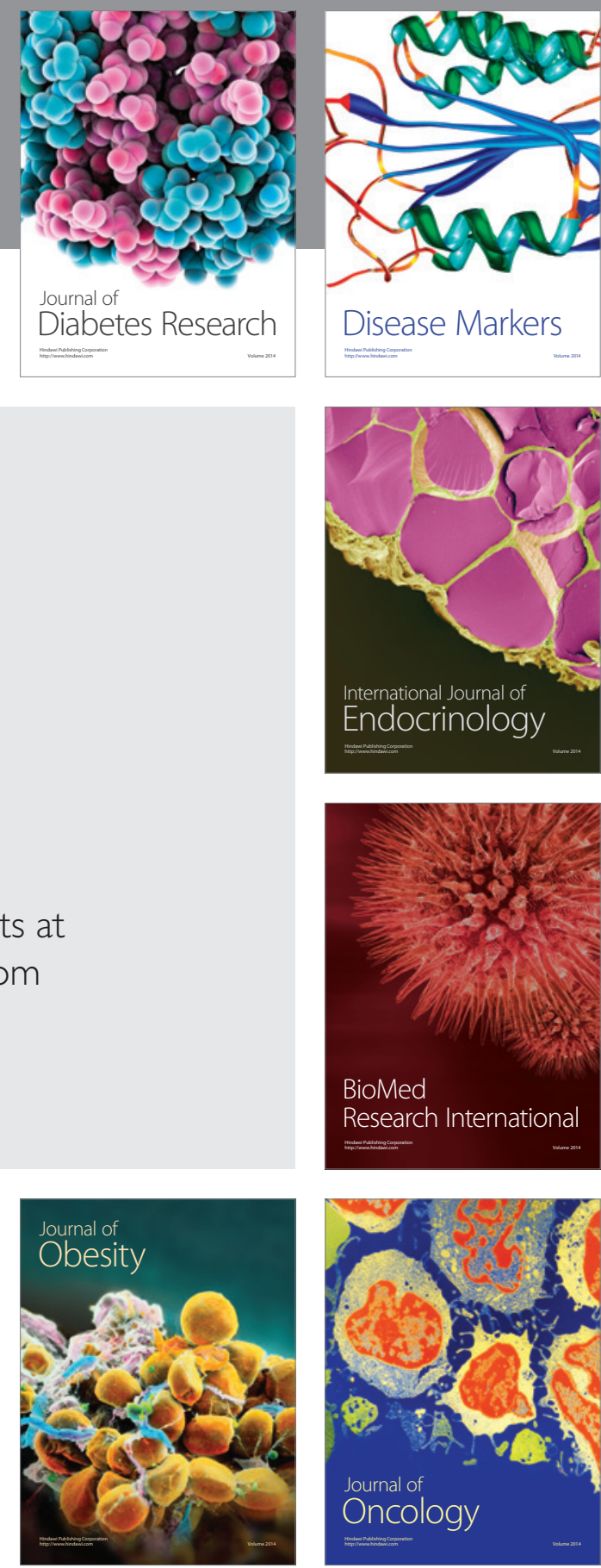

Disease Markers
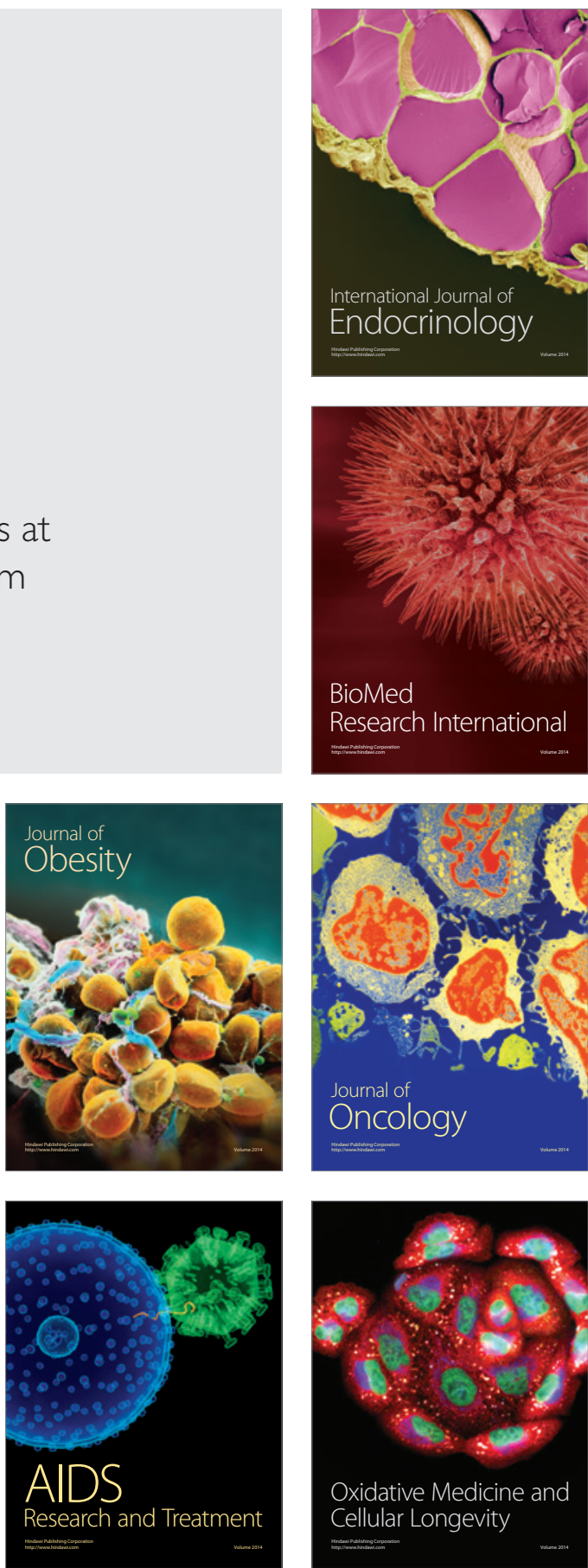